\title{
Exosomal microRNA concentrations in colorectal cancer: A mathematical model
}

\author{
Xiulan Lai ${ }^{*}$, Avner Friedman ${ }^{2}$
}

1 Institute for Mathematical Sciences, Renmin University of China, Beijing, P. R. China

2 Mathematical Bioscience Institute \& Department of Mathematics, Ohio State University, Columbus, OH, USA

*xiulanlai@ruc.edu.cn

\begin{abstract}
Colorectal cancer (CRC) is the second leading cause of cancer related deaths in the United States. Early detection increases survival very significantly. Indeed, five year survival for people diagnosed at stage I-II is $90 \%$, while for those diagnosed at stage IV it is only $13 \%$. The gold standard for early detection is colonoscopy, but this procedure is limited due to its invasive nature and its high cost. Hence there is a need to identify non-invasive biomarkers for CRC. Exosomal miRs secreted by cancer cells and overexpressed in the blood have been suggested as biomarkers for cancer. In particular, exosomal miRs 21, 23a, 92a and 1246 are overexpressed in CRC, and thus have the potential to be used as serum biomarkers for early detection of the disease. The present paper develops for the first time a mathematical model for early stage of CRC which includes the effect of these miRs on the growth of the cancer. The model is represented by a system of partial differential equations. Simulations of the model show a relationship between the growth of the tumor diameter and the total mass of these miRs under some of the common mutations which occur in CRC, namely, KRAS, PI3K, APC, p53 and SMAD mutations. The model may serve as a step toward establishing miRs 21, 23a, 92a and 1246 as reliable blood biomarkers for CRC as more experimental results and clinical data become available.
\end{abstract}

Keywords: Colorectal cancer (CRC), exosomal miR-21, miR-92a, miR-23a, miR-1246, biomarkers, mathematical model 


\section{Introduction}

Colorectal cancer (CRC) is the second leading cause of cancer-related deaths in the United 2 States [1,2]. Five-year survival rate of people diagnosed at stage I-II is 90\%, while for those 3 diagnosed at stage IV it is only $13 \%$ [2]. Hence early detection will greatly increase survival 4 rates. The gold standard method for early detection is colonoscopy. However, its widespread use 5 is limited due to its invasive nature and high cost. The most widely used non-invasive screening 6 method, the fecal occult blood test, has limited diagnostic accuracy [3]. Thus, there is a need to 7 discover new non-invasive methods.

Exosomes are nano-vesicles of size 30-100 nm in diameter, surrounded by a lipid bilayer, and containing fuctional proteins, mRNAs and microRNAs (miRs). Exosomes are released by various cells, including cancer cells [4]. A growing body of evidence suggests that exosomal miRs may be used as serum biomarkers for prognosis of CRC [5,6].

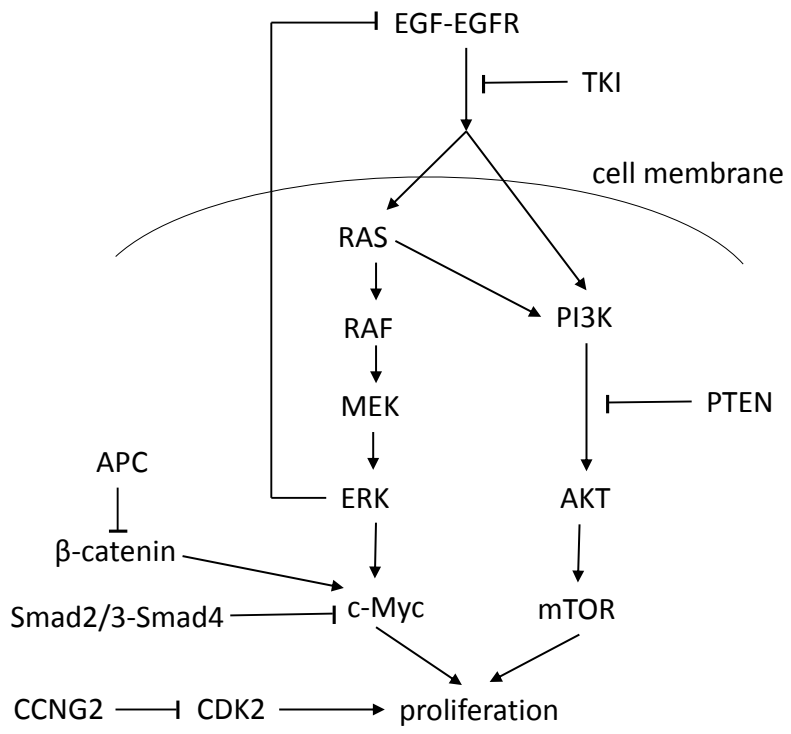

(a)

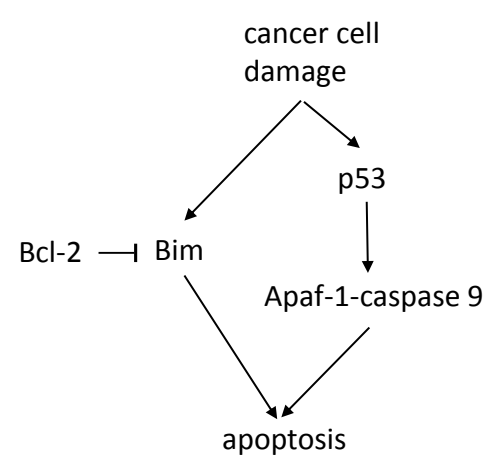

(b)

Fig. 1.The pathways of the cell proliferation and apoptosis. Sharp arrows indicate activation/enhancement and blocked arrows indicate inhibition.

Fig. 1-(a) is a schematic network showing two pathways from membrane protein EGF-EGFR 13 to cell proliferation. The first pathway is through Ras-Raf-MEK-ERK [7 9], and the second one ${ }_{14}$ is through PI3K-AKT-mTOR [9,10]. The first pathway is controlled by tyrosine kinase inhibitor 15 (TKI) and ERK [7,8], and the second one is controlled by TKI and PTEN [7,11]. Cell proliferation 16 is also controlled by blockage of c-Myc either through APC inhibition of $\beta$-catenin [12, 13], or ${ }_{17}$ by the Smad2/3-Smad4 complex [14 16]. APC is activated when the cell microenvironment is 18 too crowded, and Smad2/3 signaling is activated by hypoxic environmental conditions. Cell 19 proliferation is also modulated by CCNG2 which inhibits cyclin-dependent kinase 2 (CDK2) 20 
(through cyclin homolog G2), thereby extending the G0/G1 phase of cell cycle [17].

Fig. 1 1 (b) is a schematic network of two pathways to apoptosis when non-repairable damage occurs during the cell cycle. The first pathway goes through Bim [18, 19], a protein modulated by anti-apoptotic protein Bcl-2. The second pathway goes through p53 and Apaf-1-caspase $9{ }_{24}$ apoptosome 20, 21].

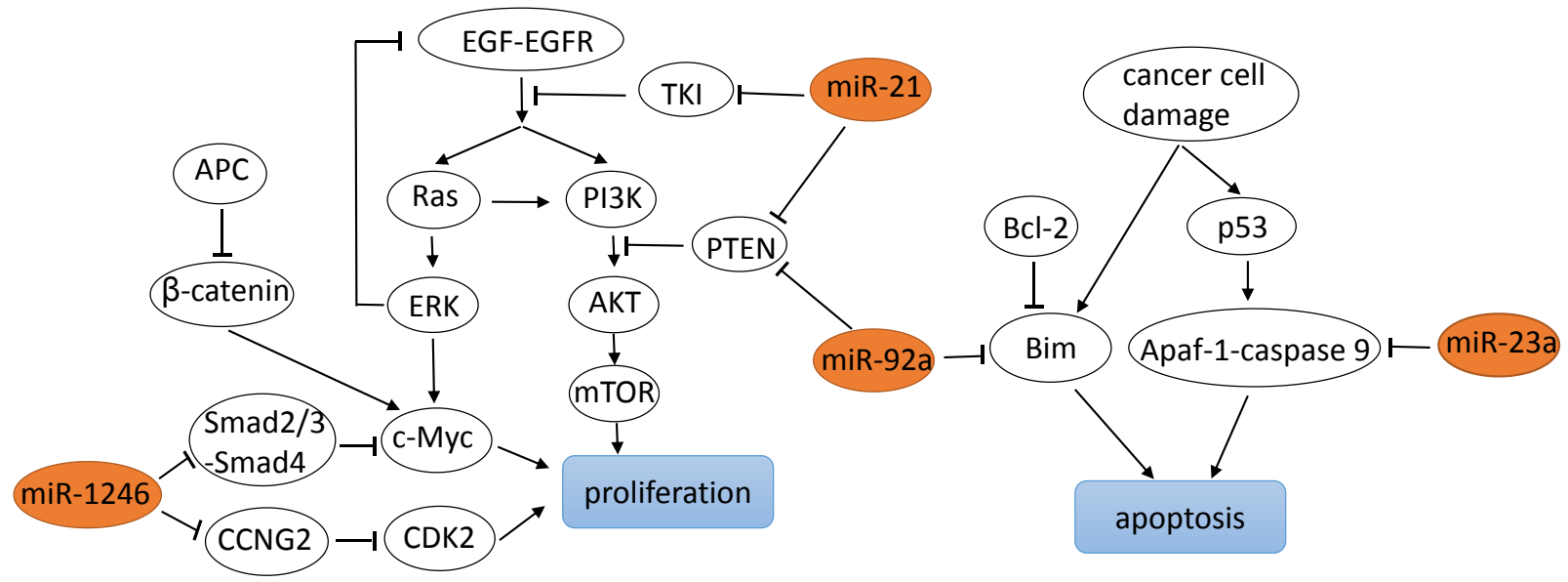

Fig. 2.The pathways of the cell proliferation and apoptosis, and the roles of miR-21, miR-92a, miR-1246 and miR-23a. Sharp arrows indicate activation/enhancement and blocked arrows indicate inhibition.

The most common mutations in CRC occur in APC, p53, PI3K, SMAD4 and KRAS [22 24]; 26 KRAS is one of the most common oncogenes of the Ras family in human cancer [25]. 27

The most overexpressed exosomal microRNAs in CRC are miR-21 [5, 6, 26], miR-23a [5, 27], 28 miR-92a [28] and miR-1246 [5, 27, 29]. Fig. 2] shows the effect of these miRs on the proliferation ${ }^{29}$ and apoptotic pathways; note that Ras-Raf-MEK-ERK pathway was abbreviated to Ras-ERK. 30 MiR-21 blocks TKI and PTEN, and thus promotes activation of the Ras-ERK and PI3K-AKT 31 pathways. MiR-1246 blocks Smad2/3 signaling [29]. Another reported target of miR-1246 is 32 CCNG2 [17]. MiR-92a targets PTEN and thus promotes the activation of AKT pathway [30,31. 33 MiR-92a also targets Bim (the Bcl-2-interacting mediator of cell death) and thus blocks the apop- $\quad 34$ tosis of colorectal cancer cells [32]. MiR-23a targets Apaf-1 and hence inhibits the formation of 35 apoptosome complex (cytochrome-c/Apaf-1/caspase-9) and blocks apoptosis of colorectal caner 36 cells [33].

The present paper develops for the first time a mathematical model which relates the growth 38 of colorectal cancer to the concentration of the exosomal miRs 21, 23a, 92a and 1246 within the 39 cancer tissue. The model is represented by a system of partial differential equations. Simulations 40 of the model establish quantitative relationship between tumor volume, under one or several of ${ }_{41}$ the common mutations in CRC, and the total mass of these miRs. The model may serve as 42 a first step toward establishing these miRs as reliable serum biomarkers for early detection of ${ }_{43}$ CRC. 
There are other miRs that are significantly abnormally expressed in CRC, but because of 45 conflicting reports they will not be included in our model. The first one is let-7a. Exosomal 46 let-7a was reported to be overexpressed in CRC patients [5], but, on the other hand, circulating ${ }_{47}$ let-7a was found to be downregulated in CRC [34, 35]. The second abnormally expressed miR in 48 CRC is miR-19 28], but its effect on cell proliferation in CRC is controversial 36, 37.

For simplicity, we drop mTOR in the PI3K-AKT-mTOR-proliferation pathway. We also 50 drop the pathway of miR-1246-CCNG2-CDK2-proliferation, since it is parallel to the (miR- 51 1246)-(Smad2/3-Smad4)-(c-Myc)-proliferation pathway.

\section{Mathematical model}

The mathematical model includes cancer cells and normal healthy cells. The cancer cells 54 shed exosomes [4]. Each exosome contains proteins, mRNAs and miRs [4]. We assume that when exosomes make contact with receptors on cancer cells, they degrade and release their content; here we focus only on the miRs. The effects of these miRs on cancer cell proliferation and apoptosis are shown in Fig. 2. The mathematical model is based on the network of Fig. 2 and is represented by a system of partial differential equations.

Equations for proteins As in [38], the dynamics of the proteins within cancer cells will 60 appear in the form

$$
\frac{d \vec{y}}{d t}=\vec{f}(\vec{y}) \frac{C}{C_{0}},
$$

where $C_{0}$ is the 'average' density of cancer cells.

Enhanced proliferation of cancer cells is associated with activation of an intracellular pathway. Associating this activation with a protein $X$, we take the enhancement rate to be proportional to

$\frac{X}{K_{X}+X}$ to reflect the limited recycling time of active $X$, where $K_{X}$ is the half-saturation value of $X$, taken as the steady state concentration of $X$ in healthy individuals. Inhibition by a protein $X$ will be represented by the factor $\frac{1}{1+X / K}$. We also assume linear natural death/degradation for all proteins and cells.

Equation for EGF-EGFR $(E)$. The equation for EGF-EGFR is given by

$$
\frac{\partial E}{\partial t}=\left[\lambda_{E} \cdot \frac{1}{1+E_{r} / K_{E E_{r}}}-d_{E} E\right] \frac{C}{C_{0}} .
$$

The coefficient $\lambda_{E}$ is the production rate of the EGF-EGFR complex and the factor $\frac{1}{1+E_{r} / K_{E_{r} E}} \quad{ }^{71}$ represents the inhibition by ERK [8]; $d_{E}$ is the degradation rate of $E$.

Equation for Ras $\left(R_{s}\right)$. The Ras-ERK pathway is activated by the EGF-EGFR [7 [9], a 73 
Table 1. List of variables in unit of $\mathrm{g} / \mathrm{cm}^{3}$.

\begin{tabular}{|l|l|}
\hline Notation & Description \\
\hline$E$ & EGF-EGFR concentration \\
$R_{s}$ & active Ras concentration \\
$E_{r}$ & active ERK concentration \\
$M$ & c-Myc concentration \\
$A_{C}$ & APC concentration \\
$P_{3}$ & PI3K concentration \\
$A$ & AKT concentration \\
$T$ & TKI concentration \\
$P$ & PTEN concentration \\
$B_{n}$ & B-catenin concentration \\
$S$ & Smad2/3 and Smad4 complex concentration \\
$P_{53}$ & p53 concentration \\
$B_{m}$ & Bim concentration \\
$B_{c}$ & Bcl-2 concentration \\
$A_{p}$ & Apaf-1-caspase 9 apoptosome concnetration \\
$E_{C}$ & cancer-shed exosome concentration \\
$m_{1}$ & miR-21 concentration \\
$m_{2}$ & miR-23a concentration \\
$m_{3}$ & miR-1246 concentration \\
$m_{4}$ & miR-92a concentration \\
$C$ & cancer cells density \\
$N$ & normal healthy cells density \\
\hline
\end{tabular}

process resisted by TKI [7]. Hence,

$$
\frac{\partial R_{s}}{\partial t}=\left[\lambda_{R s} E \cdot \frac{1}{1+T / K_{R_{s} T}}-d_{R s} R_{s}\right] \frac{C}{C_{0}},
$$

where $d_{R s}$ is the degradation rate of $R_{s}$.

$$
\frac{\partial E_{r}}{\partial t}=\left[\lambda_{E_{r}} R_{s}-d_{E_{r}} E_{r}\right] \frac{C}{C_{0}},
$$

where $d_{E_{r}}$ is the degradation rate of $E_{r}$.

Equation for $\beta$-catenin $\left(B_{n}\right)$. APC down-regulates $\beta$-catenin $[12]$; for simplicity, we do 79 not include, in the model, the dynamics of APC. In the following simulations, we assume that 80 the density of $\operatorname{APC}\left(A_{C}\right)$ is at its half-saturation value $\left(A_{C 0}\right)$ unless it is mutated. Thus the ${ }_{81}$ 
equation of $\beta$-catenin is given by

$$
\frac{\partial B_{n}}{\partial t}=\left[\lambda_{B_{n}} \frac{1}{1+A_{C} / K_{B_{n} A_{C}}}-d_{B_{n}} B_{n}\right] \frac{C}{C_{0}} .
$$

Equation for c-Myc $(M)$. c-Myc is upregulated by ERK and by $\beta$-catenin activation [13]. 83 c-Myc is repressed by the Smad complex (Smad2/3+Smad4) [14 16]. The equation of c-Myc is 84 given by

$$
\frac{\partial M}{\partial t}=\left[\left(\lambda_{M E_{r}} E_{r}+\lambda_{M B_{n}} B_{n}\right) \cdot \frac{1}{1+S / K_{M S}}-d_{M} M\right] \frac{C}{C_{0}} .
$$

Equation for AKT $(A)$. The activation of the PI3K-AKT pathway begins with the activation of PI3K $\left(P_{3}\right)$ by EGF-EGFR and Ras [9, 10. The activation of PI3K through EGF-EGFR is blocked by TKI. Hence, the equation for $P_{3}$ takes the form

$$
\frac{\partial P_{3}}{\partial t}=\left[\lambda_{P_{3} E} E \cdot \frac{1}{1+T / K_{P_{3} T}}+\lambda_{P_{3} R_{s}} R_{s}-d_{P_{3}} P_{3}\right] \frac{C}{C_{0}},
$$

where $R_{s}$ is the concentration of Ras.

AKT is activated by PI3K which is negatively regulated by PTEN, so that

$$
\frac{\partial A}{\partial t}=\left[\lambda_{A P_{3}} P_{3} \cdot \frac{1}{1+P / K_{A P}}-d_{A} A\right] \frac{C}{C_{0}} .
$$

We assume that the turnover of PI3K is very fast (the half-life of PI3K is very short [39]) and deduce from the steady state equation of $P_{3}$ that

$$
P_{3}=\frac{1}{d_{P_{3}}}\left(\lambda_{P_{3} E} E \cdot \frac{1}{1+T / K_{P_{3} T}}+\lambda_{P_{3} R_{s}} R_{s}\right) .
$$

Substituting this into the equation for AKT, we obtain

$$
\frac{\partial A}{\partial t}=\left[\left(\lambda_{A E} E \cdot \frac{1}{1+T / K_{P_{3} T}}+\lambda_{A R_{s}} R_{s}\right) \cdot \frac{1}{1+P / K_{A P}}-d_{A} A\right] \frac{C}{C_{0}},
$$

where $\lambda_{A E}=\lambda_{A P_{3}} \lambda_{P_{3} E} / d_{P_{3}}$ and $\lambda_{A R_{s}}=\lambda_{A P_{3}} \lambda_{P_{3} R_{s}} / d_{P_{3}}$.

Equation for TKI (T). The production of TKI is inhibited by miR-21. We write the 89 equation for TKI in the form

$$
\frac{\partial T}{\partial t}=\left[\lambda_{T} \cdot \frac{1}{1+m_{1} / K_{T m_{1}}}-d_{T} T\right] \frac{C}{C_{0}} .
$$

Equation for PTEN $(P)$. The expression of PTEN is inhibited by both miR-21 and 91 
miR-92a. Hence,

$$
\frac{\partial P}{\partial t}=\left[\lambda_{P} \cdot \frac{1}{1+m_{1} / K_{P m_{1}}} \cdot \frac{1}{1+m_{4} / K_{P m_{4}}}-d_{P} P\right] \frac{C}{C_{0}} .
$$

Equation for Smad complex $(S)$. The production of the Smad complex is inhibited by ${ }_{93}$ miR-1246, so that

$$
\frac{\partial S}{\partial t}=\left[\lambda_{S} \cdot \frac{1}{1+m_{3} / K_{S m_{3}}}-d_{S} S\right] \frac{C}{C_{0}},
$$

Equation for p53 $\left(P_{53}\right)$. The equation for the tumor suppressor p53 is given by

$$
\frac{\partial P_{53}}{\partial t}=\left[\lambda_{P_{53}}-d_{P_{53}} P_{53}\right] \frac{C}{C_{0}},
$$

where $\lambda_{P_{53}}$ is the production rate of p53 when it is not mutated.

Equation for Apaf-1-caspase 9 apoptosome $\left(A_{p}\right)$. The formation of the Apaf-1-caspase 9 apoptosome is up-regulated by p53 [20,21]. Apaf-1 is a target of miR-23a [33]. Hence,

$$
\frac{\partial A_{p}}{\partial t}=\left[\lambda_{A_{p}} P_{53} \cdot \frac{1}{1+m_{2} / K_{A_{p} m_{2}}}-d_{A p} A_{p}\right] \frac{C}{C_{0}},
$$

Equation for Bim $\left(B_{m}\right)$. Bim is blocked by miR-92a [32] and Bcl-2 [18,19]; for simplicity, 99 we do not include, in the model, the dynamics of Bcl-2. In the following simulations, we assume 100 that the density of Bcl-2 $\left(B_{c}\right)$ is at its half-saturation value $\left(B_{c 0}\right)$ unless it is mutated. Hence ${ }_{101}$

$$
\frac{\partial B_{m}}{\partial t}=\left[\lambda_{B_{m}} \cdot \frac{1}{1+B_{c} / K_{B_{m} B_{c}}} \cdot \frac{1}{1+m_{4} / K_{B_{m} m_{4}}}-d_{B_{m}} B_{m}\right] \frac{C}{C_{0}},
$$

Equation for exosome $\left(E_{C}\right)$. Cancer cells shed exosomes at a rate $\lambda_{E_{C}} C$, and we assume 102 that exosomes are degraded by merging with cancer cells. We assume that exosomes degrade ${ }_{103}$ when they make contact with receptor on cancer cells. Because of the limited receptor recycling 104 time, we represent the rate of degradation by the Michaelis-Menten expression $\frac{C}{K_{C}+C}$. The ${ }_{105}$ equation for the concentration of exosomes is then given by

$$
\frac{\partial E_{C}}{\partial t}-D_{E_{C}} \nabla^{2} E_{C}=\lambda_{E c} C-d_{E_{C}} E_{C} \cdot \frac{C}{K_{C}+C},
$$

where the term $D_{E_{C}} \nabla^{2} E_{C}$ represents dispersion (or diffusion).

Equations for miR-21 $\left(m_{1}\right)$, miR-23a $\left(m_{2}\right)$ and miR-1246 $\left(m_{3}\right)$. We assume that 108 miR-21, miR-23a, miR-92a and miR-1246 are released from exosomes when exosomes merge 109 with cancer cells. We take the production rate of miR-21 to be $\lambda_{m_{1}} E_{C} \cdot \frac{C}{K_{C}+C}$. Hence, the ${ }_{110}$ 
equation for $m_{1}$ is given by

$$
\frac{\partial m_{1}}{\partial t}-D_{m_{1}} \nabla^{2} m_{1}=\lambda_{m_{1}} E_{C} \cdot \frac{C}{K_{C}+C}-d_{m_{1}} m_{1}
$$

Similarly, the equations for miR-23a, miR-1246 and miR-92a are given by

$$
\begin{aligned}
& \frac{\partial m_{2}}{\partial t}-D_{m_{2}} \nabla^{2} m_{2}=\lambda_{m_{2}} E_{C} \cdot \frac{C}{K_{C}+C}-d_{m_{2}} m_{2}, \\
& \frac{\partial m_{3}}{\partial t}-D_{m_{3}} \nabla^{2} m_{3}=\lambda_{m_{3}} E_{C} \cdot \frac{C}{K_{C}+C}-d_{m_{3}} m_{3},
\end{aligned}
$$

and

$$
\frac{\partial m_{4}}{\partial t}-D_{m_{4}} \nabla^{2} m_{4}=\lambda_{m_{4}} E_{C} \cdot \frac{C}{K_{C}+C}-d_{m_{4}} m_{4} .
$$

Equation for colorectal cancer cells $(C)$. Proliferating cells grow faster than migrating cells 4042 , and the competition for space is primarily a competition with normal healthy cells (with density $N$ ). We therefore assume that the directed movement of cells is determined by the condition that the total cell density, $C+N$, is constant at each point in the tumor. The activated proliferation pathways through c-Myc and AKT are modeled by factors $\lambda_{C M} \frac{M}{K_{C M}+M}$ and $\lambda_{C A} \frac{A}{K_{C A}+A}$, respectively. The activated intrinsic apoptosis pathways by Bim 18, 19 and Apaf-1-Caspase-9 apoptosome 20,21 are modeled by factors $d_{C B_{m}} \frac{B_{m}}{K_{C B_{m}}+B_{m}}$ and $d_{C A_{p}} \frac{A_{p}}{K_{C A_{p}}+A_{p}}$, respectively. We assume that when the logistic growth of species of cells $X$ is limited by the presence of another competing (for space) species $Y$, its growth is then proportional to $X\left(1-\frac{X+\varepsilon Y}{C_{M}}\right)$ for some $0<\varepsilon \leq 1[43]$. Hence, the equation for cancer cells is given by

$$
\begin{aligned}
\frac{\partial C}{\partial t}-D_{C} \nabla^{2} C+\nabla \cdot(\mathbf{u} C)= & {\left[\lambda_{C M} \frac{M}{K_{C M}+M}+\lambda_{C A} \frac{A}{K_{C A}+A}\right] C\left(1-\frac{C+\varepsilon N}{C_{M}}\right) } \\
& -\left[d_{C A_{p}} \frac{A_{p}}{K_{C A_{p}}+A_{p}}+d_{C B_{m}} \frac{B_{m}}{K_{C B_{m}}+B_{m}}\right] C-d_{C} C,
\end{aligned}
$$

where the term $\nabla \cdot(\mathbf{u} C)$ stands for the directed movement of cells with the velocity $\mathbf{u}$.

Equation for normal healthy cells $(N)$. The equation for normal healthy cells is given by

$$
\frac{\partial N}{\partial t}-D_{C} \Delta N+\nabla \cdot(\mathbf{u} N)=\lambda_{N} N\left(1-\frac{N+\varepsilon C}{C_{M}}\right)-d_{N} N
$$

We assume, for simplicity, that the tumor is spherical and denote its moving boundary (i.e. 116 its radius) by $r=R(t)$. We also assume that all the densities and concentrations are radially 117 symmetric, that is, functions of $(r, t)$, where $0 \leq r \leq R(t)$. In particular, $\mathbf{u}=u(r, t) \mathbf{e}_{r}$, where $\mathbf{e}_{r} \quad 118$ is the unit radial vector. 
Equation for cells velocity $(u)$ : In order to determine the velocity $\mathbf{u}$, we make the as- ${ }_{120}$ sumption that the total density of all the healthy cells and cancer cells in the tumor is constant, ${ }^{121}$ $\theta$, and take

$$
N+C=\theta=0.6 \mathrm{~g} / \mathrm{cm}^{3} .
$$

We also assume that $D_{N}=D_{C}$. Adding Eqs. (2.19) and (2.18), we obtain

$$
\begin{aligned}
\frac{1}{r^{2}} \frac{\partial}{\partial r}\left(r^{2} \theta u\right)= & {\left[\lambda_{C M} \frac{M}{K_{C M}+M}+\lambda_{C A} \frac{A}{K_{C A}+A}\right] C\left(1-\frac{C+\varepsilon N}{C_{M}}\right)+\lambda_{N} N\left(1-\frac{N+\varepsilon C}{C_{M}}\right) } \\
& -\left(d_{C A_{p}} \frac{A_{p}}{K_{C A_{p}}+A_{p}}+d_{C B_{m}} \frac{B_{m}}{K_{C B_{m}}+B_{m}}\right) C-d_{C} C-d_{N} N,
\end{aligned}
$$

so that

$$
\begin{aligned}
& u(r, t)=\frac{1}{\theta r^{2}} \int_{0}^{r} \xi^{2}[\left(\lambda_{C M} \frac{M}{K_{C M}+M}+\lambda_{C A} \frac{A}{K_{C A}+A}\right) C\left(1-\frac{C+\varepsilon N}{C_{M}}\right) \\
&\left.+\lambda_{N} N\left(1-\frac{N+\varepsilon C}{C_{M}}\right)\right] d \xi \\
&\left.-\frac{1}{\theta r^{2}} \int_{0}^{r} \xi^{2}\left[\left(d_{C A_{p}} \frac{A_{p}}{K_{C A_{p}}+A_{p}}+d_{C B_{m}} \frac{B_{m}}{K_{C B_{m}}+B_{m}}\right) C+d_{C} C+d_{N} N\right)\right] d \xi .
\end{aligned}
$$

We assume that the free boundary $r=R(t)$ moves with the velocity of cells, so that

$$
\frac{d R(t)}{d t}=u(R(t), t) .
$$

Boundary conditions We impose the boundary conditions:

No-flux for $E_{C}(r, t), m_{i}(r, t),(i=1,2,3,4), C(r, t)$ and $N(r, t)$ at $r=R(t)$.

Initial conditions We assume that the concentrations of proteins TKI, PTEN, Smad com- ${ }^{126}$ plex, p53, Apaf-1 and Bim which inhibit tumor growth are initially 'relatively' high, i.e., above ${ }^{127}$ the steady state, so that they begin decrease as the tumor begins to increase. We also assume that ${ }^{128}$ the remaining proteins which are involved in promoting tumor growth, are initially 'relatively' ${ }_{129}$ low, i.e., below their steady state. One choice of initial conditions is given below: 


$$
\left\{\begin{array}{l}
R(0)=0.01 \mathrm{~cm} ; \\
E(r, 0)=6.35157 \times 10^{-4}, R_{s}(r, 0)=6.3 \times 10^{-6}, E_{r}(r, 0)=2.7552 \times 10^{-5}, \\
B_{n}(r, 0)=4.2345 \times 10^{-5}, M(r, 0)=0.6786 \times 10^{-5}, A(r, 0)=3.7448 \times 10^{-7} \\
T(r, 0)=12.7575 \times 10^{-5}, P(r, 0)=3.572 \times 10^{-7}, S(r, 0)=4.92072 \times 10^{-6}, \\
P_{53}(r, 0)=2.835 \times 10^{-6}, A p(r, 0)=4.686 \times 10^{-5}, B_{m}(r, 0)=3.0375 \times 10^{-5} \\
E_{C}(r, 0)=2.88 \times 10^{-10}, m_{i}(r, 0)=0.91 \times 10^{-12}, i=1,2,3,4 \\
C(r, 0)=0.31, N(r, 0)=0.29, \quad \text { for } 0 \leq r \leq R(0),
\end{array}\right.
$$

where the concentrations/densities are in the unit of $\mathrm{g} / \mathrm{cm}^{3}$.

\section{Results}

The system (2.1)-(2.12) is an ODE system that can be solved in terms of $C$ and $m_{i}\left(i={ }_{133}\right.$ $1,2,3,4)$, independently of the profile of the free boundary $r=R(t)$; All the variables are ${ }_{134}$ constant in time in the region where $C=0$. The remaining equations (2.13)-(2.19) form an 135 advection-diffusion system with free boundary $r=R(t)$. One can prove the existence and 136 uniqueness of a solution of the coupled system (2.1)- 2.22) for a small time interval $0 \leq t<t_{0} \quad{ }_{137}$ by the methods of [44, 45], where $t_{0}$ depends on $R(0)$. One can easily see from Eq. (2.21) that 138 $\frac{1}{r} u(r, t)$ is uniformly bounded by a constant independent of $t$, in any time interval where the 139 solution exists, so that

$$
Q R(t) \leq \frac{d R}{d t} \leq Q R(t)
$$

where $Q$ is a positive constant independent of $t$. This a priori bound enables us to extend the ${ }_{141}$ solution to all $t>0$, with $R(0) \mathrm{e}^{-Q t} \leq R(t) \leq R(0) \mathrm{e}^{Q t}$, for $0<t<\infty$.

The following simulations are based on the model Eqs. (2.1)- 2.22) with boundary conditions ${ }_{144}$ (2.23) and initial conditions 2.24). For simplicity, we did not include, in the model, the dynamics 145 of APC and of Bcl-2. In the following simulations, we assume that Bcl-2 is at its half-saturation 146 value, and that APC is also at its half-saturation value unless it is mutated. All the parameter ${ }_{147}$ values are shown in Tables 2 and 3 and the estimation of these parameters are given in Appendix ${ }_{148}$ A. 
Table 2. Summary of parameter values

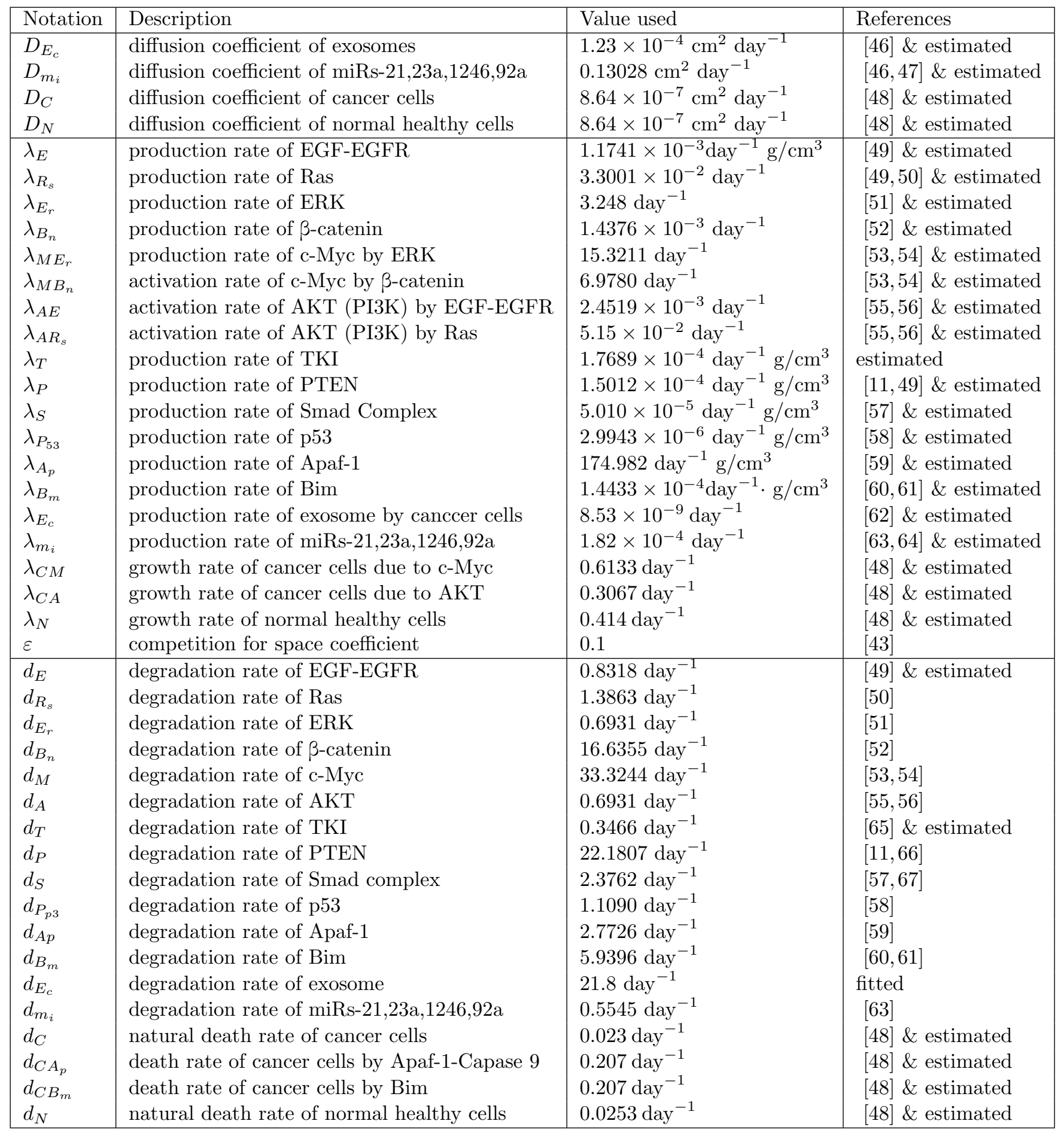


Table 3. Summary of parameter values (continued).

\begin{tabular}{|c|c|c|c|}
\hline Notation & Description & Value used & References \\
\hline$E_{0}$ & S.S. ${ }^{1}$ concentration of EGF-EGFR & $7.0573 \times 10^{-4} \mathrm{~g} / \mathrm{cm}^{3}$ & 49 \\
\hline$R_{s 0}$ & S.S. concentration of Ras & $8.4 \times 10^{-6} \mathrm{~g} / \mathrm{cm}^{3}$ & 68,69 \\
\hline$E_{r 0}$ & S.S. concentration of ERK & $3.936 \times 10^{-5} \mathrm{~g} / \mathrm{cm}^{3}$ & 68 \\
\hline$M_{0}$ & S.S. concentration of c-Myc & $1.3572 \times 10^{-5} \mathrm{~g} / \mathrm{cm}^{3}$ & 71,72 \\
\hline$A_{C 0}$ & S.S. concentration of APC & $3.1 \times 10^{-5} \mathrm{~g} / \mathrm{cm}^{3}$ & 73.74 \\
\hline$B_{n 0}$ & S.S. concentration of $\beta$-catenin & $4.321 \times 10^{-5} \mathrm{~g} / \mathrm{cm}^{3}$ & 75 \\
\hline$P_{30}$ & S.S. concentration of PI3K & $1.56 \times 10^{-6} \mathrm{~g} / \mathrm{cm}^{3}$ & 76 \\
\hline$A_{0}$ & S.S. concentration of AKT & $9.362 \times 10^{-7} \mathrm{~g} / \mathrm{cm}^{3}$ & 76 \\
\hline$T_{0}$ & S.S. concentration of TKI & $8.5050 \times 10^{-5} \mathrm{~g} / \mathrm{cm}^{3}$ & estimated \\
\hline$P_{0}$ & S.S. concentration of PTEN & $1.88 \times 10^{-7} \mathrm{~g} / \mathrm{cm}^{3}$ & 49 \\
\hline$S_{0}$ & S.S. concentration of Smad complex & $3.5148 \times 10^{-6} \mathrm{~g} / \mathrm{cm}^{3}$ & $7 \overline{78}, 79$ \\
\hline$P_{530}$ & S.S. concentration of p53 & $2.7 \times 10^{-6} \mathrm{~g} / \mathrm{cm}^{3}$ & 80 \\
\hline$A_{p 0}$ & S.S. concentration of Apaf-1-caspase 9 & $2.84 \times 10^{-5} \mathrm{~g} / \mathrm{cm}^{3}$ & 81 \\
\hline$B_{c 0}$ & S.S. concentration of $\mathrm{Bcl} 2$ & $2.5 \times 10^{-9} \mathrm{~g} / \mathrm{cm}^{3}$ & 52 \\
\hline$B_{m 0}$ & S.S. concentration of $\mathrm{Bim}$ & $2.0250 \times 10^{-6} \mathrm{~g} / \mathrm{cm}^{3}$ & 80 \\
\hline$E_{C 0}$ & S.S. concentration of C-shed exosome & $3.6 \times 10^{-10} \mathrm{~g} / \mathrm{cm}^{3}$ & 62 \\
\hline$m_{10}$ & S.S. concentration of miR-21 & $1.4 \times 10^{-12} \mathrm{~g} / \mathrm{cm}^{3}$ & 64,83 \\
\hline$m_{20}$ & S.S. concentration of miR-23a & $1.4 \times 10^{-12} \mathrm{~g} / \mathrm{cm}^{3}$ & 64,83 \\
\hline$m_{30}$ & S.S. concentration of miR- 1246 & $1.4 \times 10^{-12} \mathrm{~g} / \mathrm{cm}^{3}$ & 64,83 \\
\hline$m_{40}$ & S.S. concentration of miR-92a & $1.4 \times 10^{-12} \mathrm{~g} / \mathrm{cm}^{3}$ & 64,83 \\
\hline$C_{0}$ & S.S. density of cancer cell & $0.46 \mathrm{~g} / \mathrm{cm}^{3}$ & 84 \\
\hline$N_{0}$ & S.S. density of normal healthy cells & $0.14 \mathrm{~g} / \mathrm{cm}^{3}$ & 84 \& estimated \\
\hline$\theta$ & S.S. density of cancer and healthy cells & $0.6 \mathrm{~g} / \mathrm{cm}^{3}$ & 84 \& estimated \\
\hline$C_{M}$ & carrying capacit & $0.8 \mathrm{~g} / \mathrm{cm}^{3}$ & 84 \\
\hline$K_{E E_{r}}$ & inhibition of EGF-EGFR by ERK & $3.936 \times 10^{-5} \mathrm{~g} / \mathrm{cm}^{3}$ & 68 . 8 estimated \\
\hline$K_{R_{s} T}$ & inhibition of Ras-ERK by TKI & $8.5050 \times 10^{-5} \mathrm{~g} / \mathrm{cm}^{3}$ & estimated \\
\hline$K_{B_{n} A_{C}}$ & inhibition of $\beta$-catenin by APC & $3.1 \times 10^{-5} \mathrm{~g} / \mathrm{cm}^{3}$ & 73.74 \& estimated \\
\hline$K_{M S}$ & inhibition of c-Myc by Smad complex & $3.5148 \times 10^{-6} \mathrm{~g} / \mathrm{cm}^{3}$ & $\overline{78} \quad \overline{79}$ \& estimated \\
\hline$K_{P_{3} T}$ & inhibition of PI3K by TKI & $8.5050 \times 10^{-5} \mathrm{~g} / \mathrm{cm}^{3}$ & estimated \\
\hline$K_{A P}$ & inhibition of AKT by PTEN & $1.88 \times 10^{-7} \mathrm{~g} / \mathrm{cm}^{3}$ & 49 \& estimated \\
\hline$K_{T m_{1}}$ & inhibition of TKI by miR-21 & $0.28 \times 10^{-12} \mathrm{~g} / \mathrm{cm}^{3}$ & 64 83 \& estimated \\
\hline$K_{P m_{1}}$ & inhibition of PTEN by miR-21 & $0.28 \times 10^{-12} \mathrm{~g} / \mathrm{cm}^{3}$ & 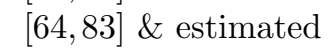 \\
\hline$K_{\mathrm{Pm}_{4}}$ & inhibition of PTEN by miR-92a & $0.28 \times 10^{-12} \mathrm{~g} / \mathrm{cm}^{3}$ & 64,83 \& estimated \\
\hline$K_{S m_{3}}$ & inhibition of Smad complex by miR-1246 & $0.28 \times 10^{-12} \mathrm{~g} / \mathrm{cm}^{3}$ & $64 \quad$ 83 \& estimated \\
\hline$K_{A_{p} m_{2}}$ & inhibition of Apaf- 1 by miR-23a & $0.28 \times 10^{-12} \mathrm{~g} / \mathrm{cm}^{3}$ & 64, \&3 \& estimated \\
\hline$K_{B_{m} m_{4}}$ & inhibition of Bim by miR-92a & $0.28 \times 10^{-12} \mathrm{~g} / \mathrm{cm}^{3}$ & $64 \quad$ \&3 estimated \\
\hline$K_{B_{m} B_{c}}$ & inhibition of Bim by Bcl-2 & $2.5 \times 10^{-9} \mathrm{~g} / \mathrm{cm}^{3}$ & 52 \& estimated \\
\hline$K_{P_{3} R_{s}}$ & half-saturation of Ras in PI3K activation & $8.4 \times 10^{-6} \mathrm{~g} / \mathrm{cm}^{3}$ & 68 69 \& estimated \\
\hline$K_{C}$ & half-saturation of cancer cell on merging with exosome & $0.46 \mathrm{~g} / \mathrm{cm}^{3}$ & 84 \& estimated \\
\hline$K_{C M}$ & half-saturation of c-Myc on cancer cell proliferation & $1.3572 \times 10^{-5} \mathrm{~g} / \mathrm{cm}^{3}$ & 71 , 72 \& estimated \\
\hline$K_{C A}$ & half-saturation of AKT on cancer cell proliferation & $9.362 \times 10^{-7} \mathrm{~g} / \mathrm{cm}^{3}$ & 49 \& estimated \\
\hline$K_{C A_{p}}$ & half-saturation of Apaf-1 on cancer cell apoptosis & $2.84 \times 10^{-5} \mathrm{~g} / \mathrm{cm}^{3}$ & 81 \& estimated \\
\hline$K_{C B_{m}}$ & half-saturation of Bim on cancer cell apoptosis & $2.0250 \times 10^{-6} \mathrm{~g} / \mathrm{cm}^{3}$ & 80 \& estimated \\
\hline
\end{tabular}

${ }^{1}$ S.S. refers to steady state. 


\subsection{Tumor growth}

Fig. 3 shows the average concentrations of all the variables over a period of 60 days. Most 151 of the concentrations are either monotone increasing or monotone decreasing in time: the cell ${ }_{152}$ growth inhibitors TKI, PTEN, Smad complex, p53, Apaf-1 and Bim are decreasing, while the ${ }_{153}$ cell growth promoters are increasing. The only exception is the average concentration of $E$. It ${ }_{154}$ is initially increasing since Ras and ERK densities are small. But Ras and ERK continue to 155 increase (as the average density of TKI keeps decreasing), and after a few days the inhibition by ${ }_{156}$ ERK (see Fig 1) forces $E$ to decrease, and it does so until it reaches a steady state.
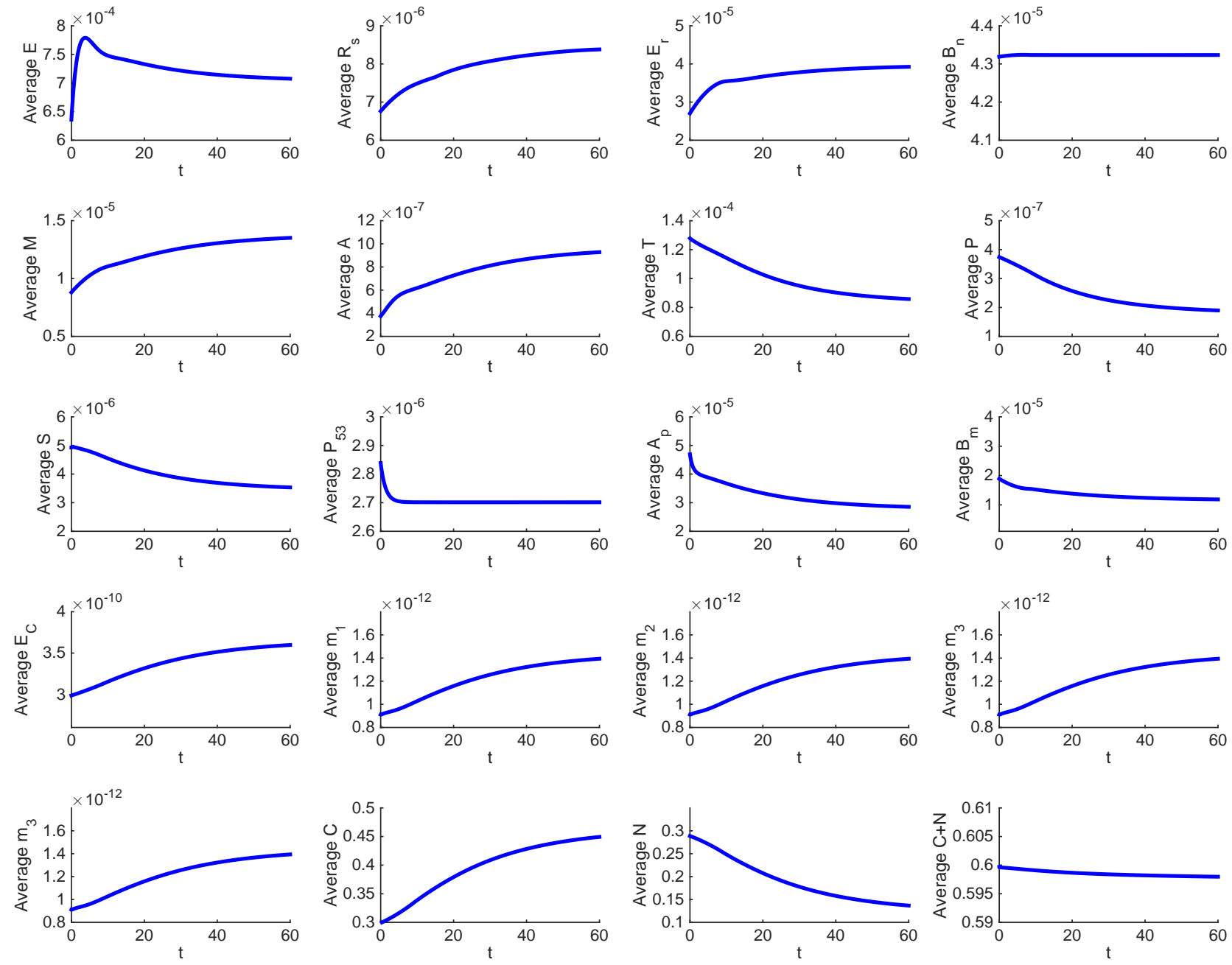

Fig. 3. Average densities/concentrations of all the variables in the model. All parameter values are as in Tables 2 and 3

We note that in estimating some of the parameters we assumed steady-state of the various ${ }_{158}$ variables (cells, proteins, miRs). The steady states of the variables in Fig. 3 agree approximately 159 with those steady state values, thereby establishing the consistency of our assumed steady-state 160 
values. In particular, the average density of cancer cells stabilize at $0.4593 \mathrm{~g} / \mathrm{cm}^{3}$, and the average $\quad 161$ density of normal healthy cells stabilize at $0.1397 \mathrm{~g} / \mathrm{cm}^{3}$, while $C+N$ remains approximately ${ }_{162}$ equal to $0.6 \mathrm{~g} / \mathrm{cm}^{3}$ at the entire time.
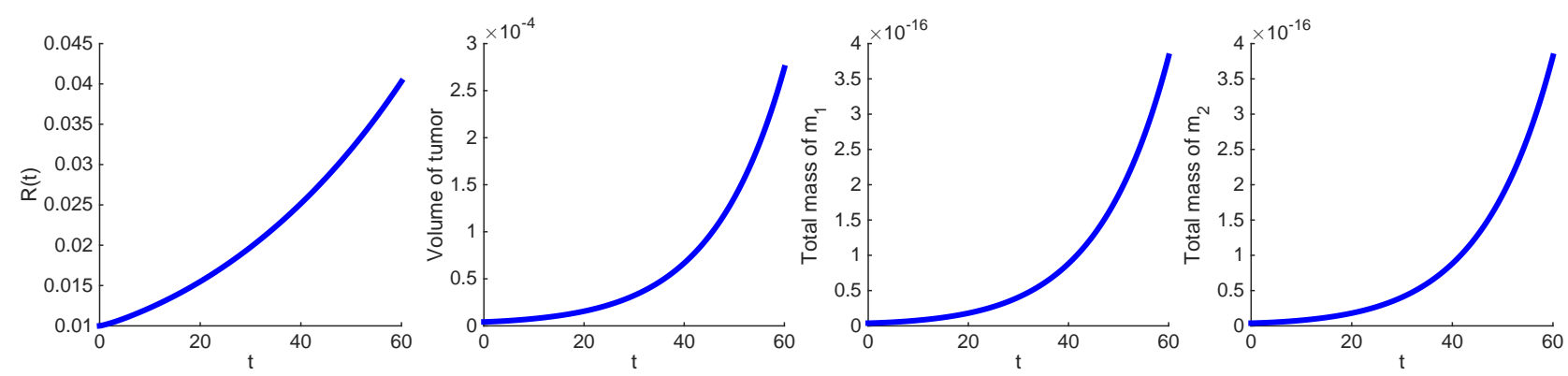

Fig. 4. The growth of tumor radius $R(t)$, tumor volume, total mass of $m_{1}$, and total mass of $m_{2}$ for the first 60 days. All parameter values are as in Tables 2 and 3.

Fig 4 shows the growth of the tumor radius and volume, and of the total mass of $m_{1}$ and ${ }_{164}$ $m_{2}$ for the first 60 days; the growth of $m_{3}$ and $m_{4}$ are the same as the growth of $m_{1}$ (not shown ${ }_{165}$ here). From these profiles we can deduce relations between the total volume of the tumor and 166 the total mass of $m_{1}$ and of $m_{2}$ for the first 60 days. These relations are shown in Fig 5 .
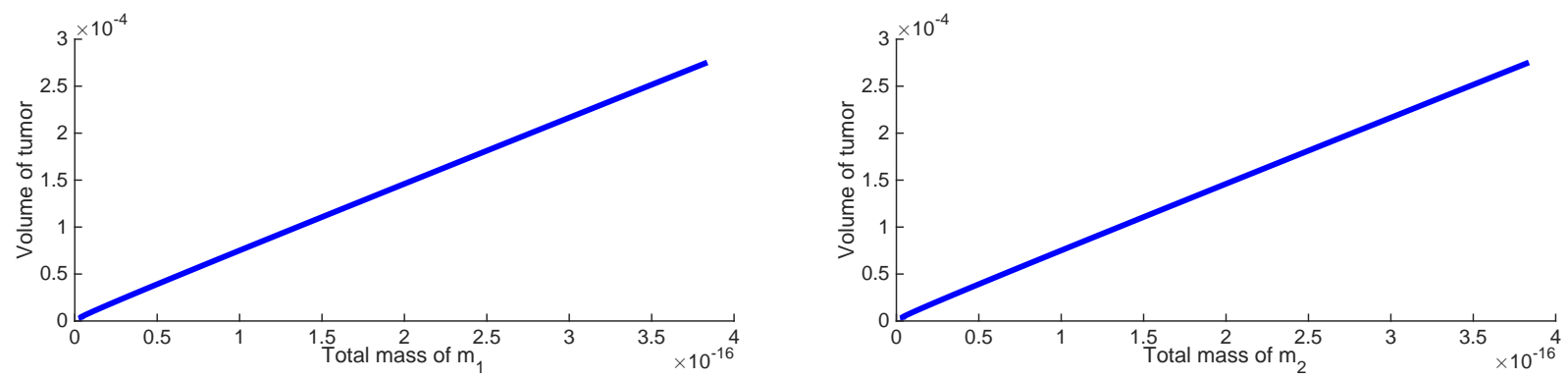

Fig. 5. Volume of tumor as a function of the total mass of miR-21, of miR-23a and of miR-1246 after the first 60 days. All parameter values are as in Tables 2 and 3 .

Fig 5 suggests that miR-21, miR-23a, miR-1246 and miR-92a could be used as biomarkers 168 for determining the volume of CRC when this volume is still extremely small.

\subsection{Treatment}

It is well known that cancer cells in CRC lose sensitivity to anti-tumor drugs, for example to ${ }_{171}$ 5-fluorouracil (5-FU), oxaliplatin and difluorinated curcumin (CDF), and that some anti-miRs 172 can restore this sensitivity. For example, anti-miR-21 was shown to increase the sensitivity of 173 cancer cells to 5-FU chemotherapy in patient data 85] and in vitro experiments with colon cancer 174 cell line HT-29 [86]. We use our model to explore the effect of anti-miR combined with these 175 
drugs. For simplicity, we ignore negative side-effects and, in particular, assume that the effect of 176 the drugs on normal healthy cells is negligible.

5-FU inhibits thymidylate synthase which leads to DNA damages and activation of p53 [87]. 178 Oxaliplatin causes DNA damage and apoptosis through formation of DNA lesions, arrest of ${ }_{179}$ DNA synthesis and inhibition of RNA synthesis [88]. Thus the combination of 5-fluorouracil and 180 oxaliplatin (FUOX) causes DNA damage and apoptosis. Experiments in vitro by Yu et al. [36] 181 show that anti-miR-21 reduces cellular growth in colon cancer, and the combination of FUOX 182 and anti-miR-21 demonstrated greater ability to reduce cancer cell proliferation than either agent 183 administered alone. We can use our model to represent these experimental results. We account 184 for the effect of FUOX by increasing $\lambda_{P_{53}}$ to $1.3 \lambda_{P_{53}}$ and the effect of anti-miR-21 by reducing 185 $\lambda_{m_{1}}$ to $\lambda_{m_{1}} / 2$. Fig 6-(a) shows that FUOX alone reduces the growth of tumor volume, but in 186 combination with anti-miR-21 the reduction is significantly larger, in qualitative agreement with 187 the results in $[36]$.
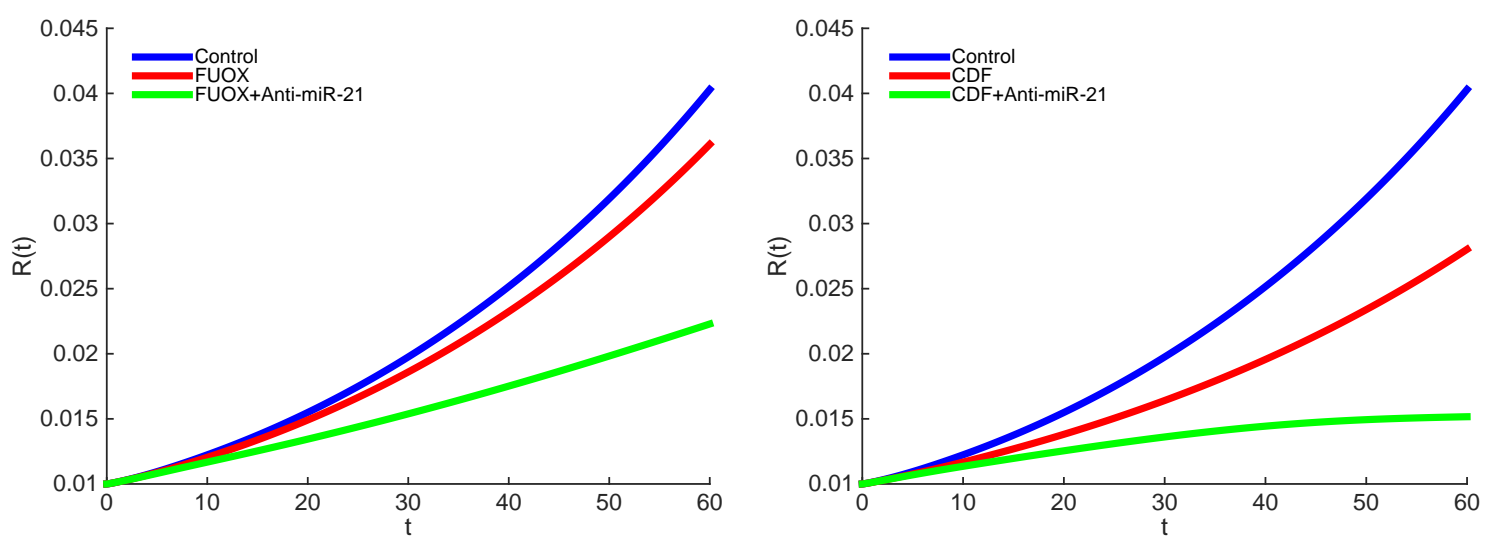

Fig. 6. Tumor growth under different drugs. (a) FUOX induces cell damage and leads to cell apoptosis. In the model, $\lambda_{P_{53}}$ is increased to $1.3 \lambda_{P_{53}}$; anti-miR-21 is accounted for by reducing $\lambda_{m_{1}}$ to $\lambda_{m_{1}} / 2$. (b) CDF inhibits EGFR and also increases tumor apoptosis, which is is accounted for by decreasing $\lambda_{E}$ to $\lambda_{E} / 1.2$ and increasing $\lambda_{P_{53}}$ and $\lambda_{B_{m}}$ to $1.3 \lambda_{P_{53}}$ and $1.2 \lambda_{B_{m}}$; anti-miR-21 is accounted for by reducing $\lambda_{m_{1}}$ to $\lambda_{m_{1}} / 2$. All other parameter values are as in Tables 2 and 3 .

CDF is a drug that targets EGFR, up-regulates p53 expression, and down-regulates Bcl-2 189 expression [89 91. Experiments in vitro by Yu et al. [36] show that the combination of CDF and 190 anti-miR-21 demonstrated greater ability to reduce cancer cell proliferation than either agent 191 administered alone. Furthermore, the reduction in cell growth is higher for the combination 192 of CDF and anti-miR-21 than the combination of FUOX and anti-miR-21. The simulations in 193 Fig.6-(b) mimic this experiment; the effect of CDF is accounted for decreasing $\lambda_{E}$ to $\lambda_{E} / 1.2194$ and increasing $\lambda_{P_{53}}$ to $1.3 \lambda_{P_{53}}$ and $\lambda_{B_{m}}$ to $1.2 \lambda_{B_{m}}$; the effect of anti-miR-21 is accounted for, as 195 before, by reducing $\lambda_{m_{1}}$ to $\lambda_{m_{1}} / 2$. 196

Fig. 7 shows the effect of a single mutation of oncogenes on the tumor radius $R(t)$ and the ${ }_{197}$ 
total mass of miR-21 (with concentration $m_{1}$ ); the effects on the growth of the total mass of 198 miR-23a, of miR-1256 and of miR-92a are similar (not shown here). The left panel profiles $R(t) \quad{ }_{199}$ and the right shows the total mass of $m_{1}$ under mutations of oncogenes KRAS and PI3K. In the 200 model, we represent the mutations by increasing corresponding growth rates of $\lambda_{R_{s}}, \lambda_{P_{3} E}$ and 201 $\lambda_{P_{3} R_{s}}$ (i.e $\lambda_{A E}$ and $\lambda_{A R_{s}}$ ) by a factor 4 . From Fig. 7 we see that for same magnitude of mutations ${ }_{202}$ of KRAS and PI3K, KRAS has stronger effect on the growth of tumor radius and total mass of ${ }_{203}$ $m_{1}$.
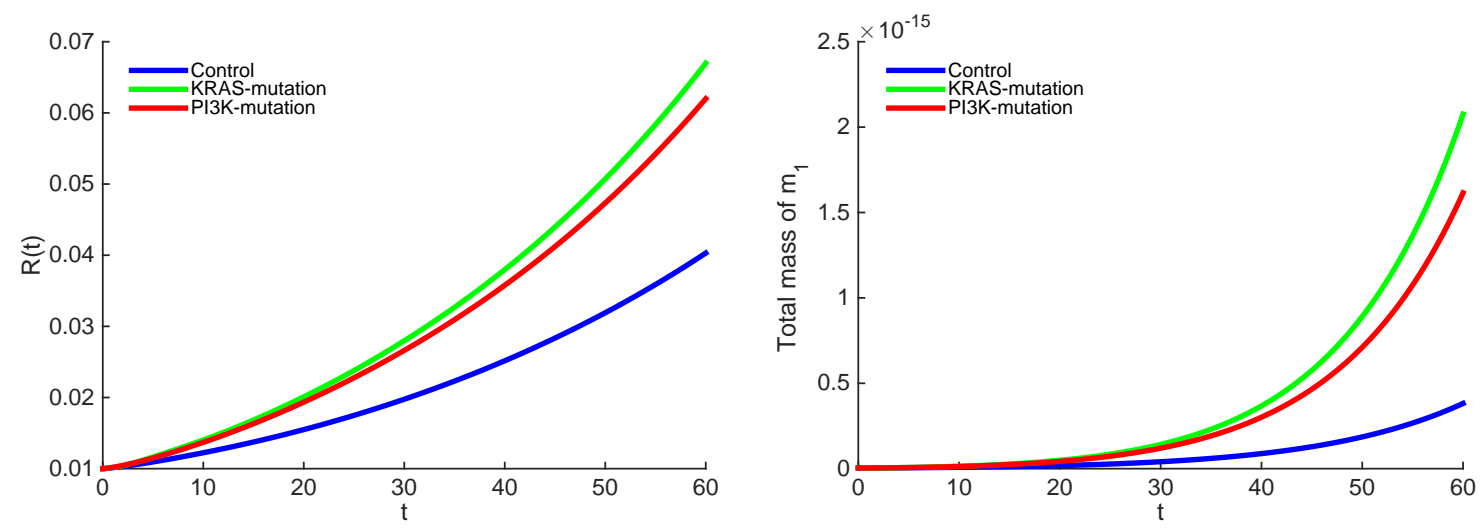

Fig. 7. Growth of tumor radius and the total mass of miR-21 and miR-92a (with concentration $m_{1}$ ) under different mutations in oncogenes. Mutation in KRAS is accounted by increasing and $\lambda_{R_{s}}$ by factor 4; mutation in PI3K is accounted for by increasing $\lambda_{P_{3} E}$ and $\lambda_{P_{3} R_{s}}$ (i.e $\lambda_{A E}$ and $\lambda_{A R_{s}}$ ) by factor 4 . All other parameter values are as in Tables 2 and 3 .
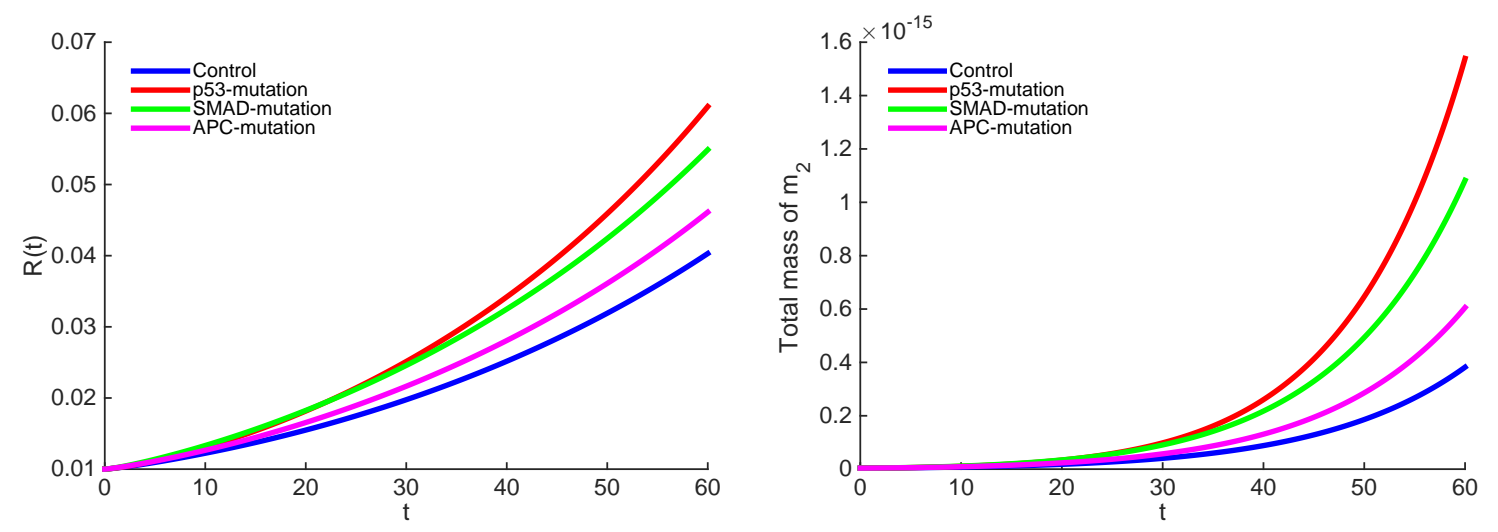

Fig. 8. Growth of tumor radius and the total mass of miR-23a (with concentration $m_{2}$ ) under different mutations in tumor suppressor genes. Mutations in p53, Smad and APC are accounted for by decreasing $\lambda_{P_{53}}$ and $\lambda_{S}$ to $\lambda_{P_{53}} / 2$ and $\lambda_{S} / 2$, and decreasing $A_{C}$ to $A_{C} / 2$. All other parameter values are as in Tables 2 and 3 .

Fig. 8 shows the effect of a single mutation of tumor suppressor genes on growth of tumor 205 radius $R(t)$ and the total mass of miR-23a (with concentration $m_{2}$ ). The effects on the growth of 206 
the total mass of $m_{1}$, of $m_{3}$ and of $m_{4}$ are similar (not shown here). The left panel profiles $R(t) \quad{ }_{207}$ and the right panel shows the growth total mass of $m_{2}$ under mutations of suppressor genes p53, 208 SMAD and APC, where we decreased the growth rate of each of these genes only by the factor 209 2 (which is half the factor than that we increased for oncogene mutations), for the following 210 reason: Mutation of one copy of an oncogene already leads to abnormal proliferation, whereas ${ }^{211}$ silencing suppressor genes requires both copies of the gene to be mutated. Fig. 8 shows that p53 ${ }_{212}$ mutation has significantly stronger impact than SMAD and APC mutations.

In actual colorectal cancer, one typically detects several gene mutations, not just one or two. ${ }^{214}$ Fig. 9 shows the growth of tumor radius and the total mass of miR-21 under mutations of both 215 oncogene KRAS and tumor suppressor gene p53. We see that the combined mutations in KRAS ${ }_{216}$ and p53 result in more significant growth of the tumor and of the total mass of $m_{1}$ than in a 217 single mutation.
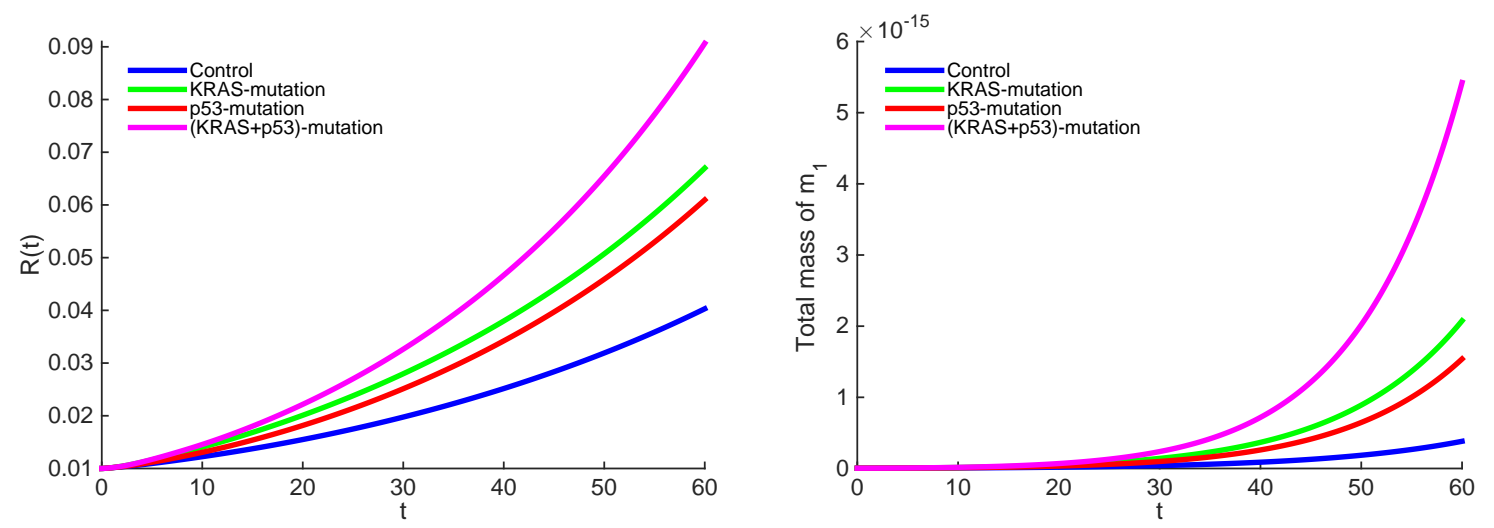

Fig. 9. Growth of tumor radius and the total mass of miR-21 (with concentration $m_{1}$ ) under mutations of KRAS and p53. Mutations in KRAS is accounted for by increasing $\lambda_{R_{s}}$ to $4 \lambda_{R_{s}}$; mutations in p53 is accounted for by decreasing $\lambda_{P_{53}}$ to $\lambda_{P_{53}} / 2$. All other parameter values are as in Tables 2 and 3 .

\section{Conclusion}

Colorectal cancer (CRC) is the second leading cause of cancer-related deaths in the United 220 States. Five year survival greatly increases for those diagnosed at early stages. The gold standard ${ }_{221}$ for early detection is colonoscopy. However this procedure is invasive and incurs high costs. For 222 these reasons current research aims at discovering reliable non-invasive biomarkers. A growing ${ }^{223}$ body of evidence suggests that microRNAs from cancer-related exosomes may be used as serum 224 biomarkers for diagnosis of malignant tumors [92, 93] and, in particular, for CRC [5, 6]. ${ }^{225}$

The present paper develops a mathematical model which relates the growth of CRC to the ${ }_{226}$ concentration of exosomal miRs. The most overexpressed exosomal miRs in the blood of CRC 227 patients include miR-21, miR-23a, miR-92a and miR-1246. Overexpressed miR-21, miR-92a 228 
and miR-1246 increase cancer proliferation, while overexpressed miR-23a and miR-92a decrease ${ }_{229}$ cancer cells apoptosis. The mathematical model is based on a gene network that includes the 230 pathways through which these miRs interact to promote CRC progression. In order to focus 231 on early stages of the disease, the model includes only cancer cells and healthy normal cells. 232 Simulations of the model yield quantitative relationships between the dynamics of the growing 233 diameter of the tumor and the increasing mass of the above miRs.

The most common mutations seen in CRC patients occur in APC, p53, KRAS, PI3K and 235 SMAD 22 24]. Simulations of the model show how these mutations affect the diameter of the 236 tumor and the corresponding total mass of the miRs. Thus, a level of overexpression (at any 237 time $t$ ) of these miRs in tissue informs on the size of the tumor. 238

The present model should be viewed as a step toward establishing the above miRs as reliable ${ }_{239}$ serum biomarkers for early detection of CRC. Future progress will require to determine precisely 240 how the blood concentration of each of above four miRs relate to its tissue concentration in 241 the tumor. Furthermore, when more clinical data become available, some of the parameters of 242 the model could then be determined more precisely to make the model predictions agree with 243 patients data and to test and validate the model on new clinical data. The model could then ${ }^{244}$ be used not only as diagnostic tool, but also as a prognostic tool, for instance to suggest how 245 targeting some of the above miRs will increase the sensitivity of cancer cells to chemotherapeutic 246 drugs.

\section{Sensitivity analysis}

We performed sensitivity analysis on some of the production parameters of the system (2.1)- 249 (2.22), and the important parameter $d_{E c}$ (which was only fitted). Following the method of [94], 250 we performed Latin hypercube sampling and generated 1000 samples to calculate the partial ${ }_{251}$ rank correlation coefficients (PRCC) and the p-values with respect to the tumor radius at day ${ }^{252}$ 60. In sampling the production rates of the proliferation pathway of Ras $\rightarrow$ c-Myc we varied the ${ }_{253}$ vector $\left(\lambda_{R s}, \lambda_{E_{r}}, \lambda_{M E_{r}}\right)$ by the same factor $\eta_{1}, \frac{1}{2} \leq \eta_{1} \leq 2$. Similarly, we varied the productions ${ }_{254}$ rates in the apoptosis pathway of p53 $\rightarrow$ Apaf-1-Caspase $9,\left(\lambda_{P_{53}}, \lambda_{A_{p}}\right)$ by the same factor $\eta_{2}, \quad 255$ $\frac{1}{2} \leq \eta_{2} \leq 2$. For all other parameters $\lambda_{A E_{r}}, \lambda_{S}, \lambda_{m_{i}}$ and $d_{E c}$, we took the range of each from $1 / 2{ }_{256}$ to twice its values in Table 2. The results are shown in Fig 10. 257

We see that the production rates that increase proliferation through oncogene activation, 258 namely, $\left(\lambda_{R_{S}}, \lambda_{E_{r}}, \lambda_{M E_{r}}\right)$ and $\lambda_{A E}$ are positively correlated to tumor radius. On the other hand, 259 the production rates of the cell-replication inhibitor SMAD, $\lambda_{S}$, and the production rates of 260 apoptosis-promotors $\left(\lambda_{P_{53}}, \lambda_{A_{p}}\right)$ are negatively correlated to tumor radius. Since miR-21 blocks ${ }_{261}$ the inhibitors TKI $(T)$ and PTEN $(P)$, so if $\lambda_{m_{1}} E_{C}$ grows the tumor volume will increase. Hence ${ }_{262}$ $\lambda_{m_{1}}$ is positively correlated and $d_{E c}$ is negatively correlated. MiR-23a blocks the Apaf-1 activa- ${ }^{263}$ 


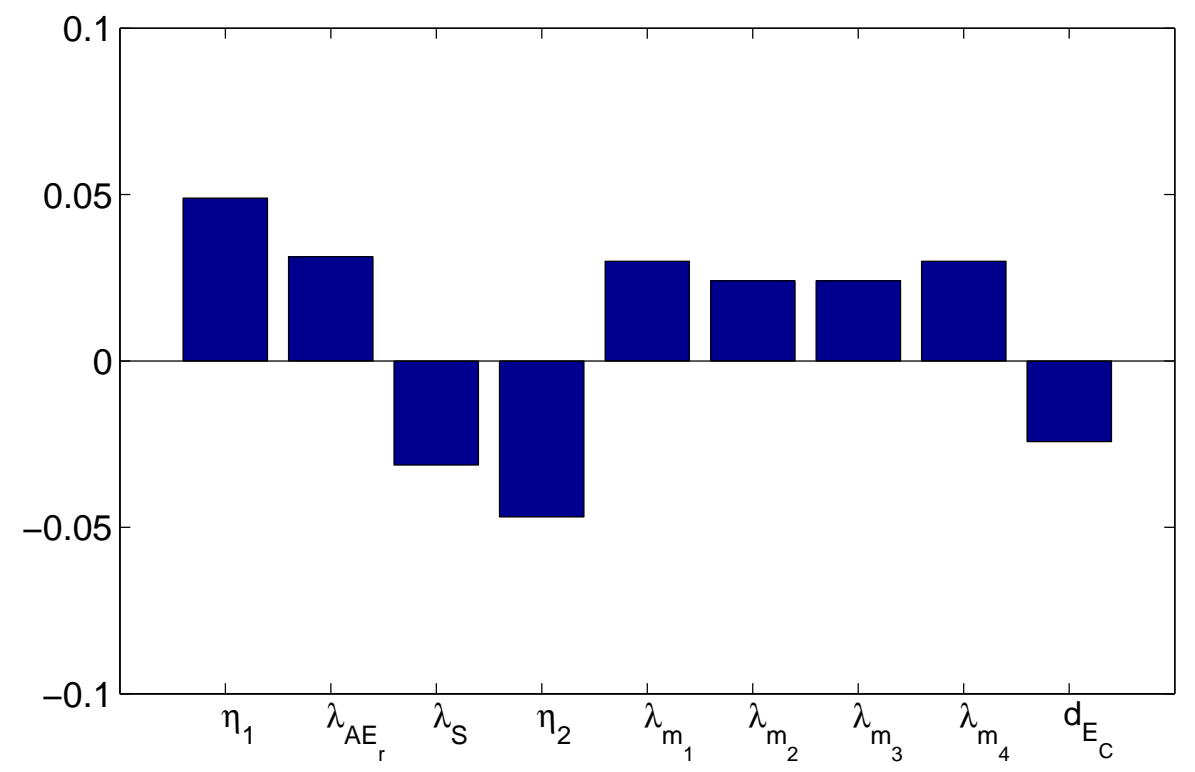

Fig. 10. Statistically significant $\mathbf{P R C C}$ values (p-value $<0.01$ ) for $R(t)$ at day 60 .

tion and hence apoptosis, so $\lambda_{m_{2}}$ is positively correlated. MiR-1246 blocks SMAD $(S)$, so $\lambda_{m_{3}}{ }^{264}$ is positively correlated. MiR-92a blocks inhibitor PTEN and apoptosis promotor Bim $\left(B_{m}\right)$, so ${ }^{265}$ $\lambda_{m_{4}}$ is positively correlated. 266

\section{Acknowledgments}

This work is supported by the Mathematical Biosciences Institute and the National Science ${ }_{269}$ Foundation (Grant DMS 0931642), the National Natural Science Foundation of China (Grant No. 270 11501568), and the Fundamental Research Funds for the Central Universities and the Research ${ }^{271}$ Funds of Renmin University of China.

\section{Appendix A. Parameter estimation}




\section{Steady state concentrations}

In some estimating parameters, we use steady state equations; we denote the steady state ${ }_{277}$ concentrations of species $X$ by $X_{0}$.

EGF-EGFR Cancer cells express $2-3 \times 10^{6}$ EGFR proteins per cell [49]. We take the average ${ }^{279}$ to be $2.5 \times 10^{6}$ EGFR per cell, or $\frac{2.5 \times 10^{6}}{N_{A}}$ fraction of a mole, per cell, where $N_{A}=6.022 \times 10^{23}{ }^{280}$ is Avogadro's number. The molecular weight of EGFR is $170 \mathrm{kDa}$ [49]. By Eq. (5.1), the mass ${ }^{281}$ of EGFR in one cell is $\frac{2.5 \times 10^{6}}{N_{A}} \times 170 \times 10^{3} \mathrm{~g}=7.0573 \times 10^{-13} \mathrm{~g}$. Assuming that one cell has a ${ }^{282}$ volume of $10^{-9} \mathrm{~cm}^{3}$, we find that the concentration of EGFR is $7.0573 \times 10^{-4} \mathrm{~g} / \mathrm{cm}^{3}$. We ${ }^{283}$ assume that the concentration of EGF-EGFR is not limited by the availability of EGF, so that ${ }^{284}$ $E_{0}=7.0573 \times 10^{-4} \mathrm{~g} / \mathrm{cm}^{3}$.

Ras The molar concentration of Ras is $0.4 \mu \mathrm{M}[68$ and its molecular weight is $21 \mathrm{kDa}[69] .286$ Hence, by Eq. (5.2), the concentration of Ras is $R_{s 0}=\left(0.4 \times 10^{3}\right) \times 21 \times 10^{-9} \mathrm{~g} / \mathrm{cm}^{3}=8.4 \times \quad{ }^{287}$ $10^{-6} \mathrm{~g} / \mathrm{cm}^{3}$.

ERK The molar concentration of ERK is $0.96 \mu \mathrm{M}[68,69]$ and its molecular weight is $41 \mathrm{kDa}{ }^{289}$ [70]. Hence the concentration of MEK is $E_{r 0}=\left(0.96 \times 10^{3}\right) \times 41 \times 10^{-9} \mathrm{~g} / \mathrm{cm}^{3}=3.936 \times 10^{-5} \mathrm{~g} / \mathrm{cm}^{3}$. $\quad 290$

c-Myc The molar concentration of c-Myc is $0.2189 \mu \mathrm{M}[71]$ and its molecular weight is $62 \mathrm{kDa} 291$ [72]. It follows that the concentration of c-Myc is $M_{0}=\left(0.2189 \times 10^{3}\right) \times 62 \times 10^{-9} \mathrm{~g} / \mathrm{cm}^{3}={ }_{292}$ $1.3572 \times 10^{-5} \mathrm{~g} / \mathrm{cm}^{3}$.

APC The molar concentration of APC is 100nM [73] and its molecular weight is 310kDa [74]. Hence the concentration of APC is $A_{C 0}=100 \times 310 \times 10^{-9} \mathrm{~g} / \mathrm{cm}^{3}=3.1 \times 10^{-5} \mathrm{~g} / \mathrm{cm}^{3}$.

$\beta$-Catenin The molar concentration of $\beta$-Catenin is $490 \mathrm{nM}[75$ and its molecular weight 296 is $88 \mathrm{kDa} 95$. Hence the concentration of $\beta$-Catenin is $B_{n 0}=490 \times 88 \times 10^{-9} \mathrm{~g} / \mathrm{cm}^{3}=4.321 \times{ }_{297}$ $10^{-5} \mathrm{~g} / \mathrm{cm}^{3}$.

PI3K The molar concentration of PI3K is $8 \mathrm{nM}$ [76,77], and its molecular weight is $195 \mathrm{kDa} 299$ [96]. From Eq. 5.2, we find that the concentration of PI3K is $P_{30}=8 \times 195 \times 10^{-9} \mathrm{~g} / \mathrm{cm}^{3}=300$ $1.56 \times 10^{-6} \mathrm{~g} / \mathrm{cm}^{3}$.

AKT The molar concentration of AKT is $15.1 \mathrm{nM}[49]$, and its molecular weight is $62 \mathrm{kDa} 302$ [49]. According to Eq. (5.2), the concentration of AKT is then $A_{0}=15.1 \times 62 \times 10^{-9} \mathrm{~g} / \mathrm{cm}^{3}={ }_{303}$ $9.362 \times 10^{-7} \mathrm{~g} / \mathrm{cm}^{3}$.

PTEN The molar concentration of PTEN is $4 \mathrm{nM}$ [97], and its molecular weight is 47kDa [97]. 305 Applying Eq. 5.2 , we find that the concentration of PTEN is $P_{0}=4 \times 47 \times 10^{-9} \mathrm{~g} / \mathrm{cm}^{3}=1.88 \times 306$ $10^{-7} \mathrm{~g} / \mathrm{cm}^{3}$.

TKI TKI inhibits the activation of PI3K, and PTEN inhibits the activation of AKT. We 308 assume that these two inhibitions are proportional, that is $T_{0} / E_{0}=P_{0} / P_{30}$, and we get $T_{0}={ }^{309}$ $P_{0} E_{0} / P_{30}=8.5050 \times 10^{-5} \mathrm{~g} / \mathrm{cm}^{3}$.

Smad complex The concentration of Smad2/3 is $60.6 \mathrm{nM}[78]$ and its molecular weight is 55- 311 $60 \mathrm{kDa}[79]$; we choose it to be $58 \mathrm{kDa}$. The concentration of Smad4 is $50.8 \mathrm{nM}[78]$ and its molec- 312 
ular weight is $60 \mathrm{kDa}[79]$. In $\mathrm{g} / \mathrm{cm}^{3}$ unit these concentrations are $60.6 \times 58 \times 10^{-9} \mathrm{~g} / \mathrm{cm}^{3}=3.5148 \times \quad 313$ $10^{-6}$ and $50.8 \times 60 \times 10^{-95}=3.048 \times 10^{-6}$. Accordingly we take the concentration of the $\operatorname{Smad} 2 / 3-\quad 314$ Smad4 complex to be $S_{0}=3.5148 \times 10^{-6} \mathrm{~g} / \mathrm{cm}^{3}$.

p53 The concentration of p53 is $2.7 \times 10^{-6} \mathrm{~g} / \mathrm{cm}^{3}[80]$.

Apaf-1 The molar concentration of Apaf-1 ranges from $0.1 \mu \mathrm{M}$ to $0.5 \mu \mathrm{M}[81]$. We take it to 317 be $0.2 \mu \mathrm{M}$. The molecular weight of Apaf-1 is $142 \mathrm{kDa}[81$. Hence, by Eq. (5.2), the concentration 318 of Apaf- 1 is $\left(0.2 \times 10^{3}\right) \times 142 \times 10^{-9} \mathrm{~g} / \mathrm{cm}^{3}=2.84 \times 10^{-5} \mathrm{~g} / \mathrm{cm}^{3}$. We assume that the concentration 319 of Apaf-1-caspase- 9 apoptosome is not limited by the availability of caspase 9 , so that $A_{p 0}={ }_{320}$ $2.84 \times 10^{-5} \mathrm{~g} / \mathrm{cm}^{3}$.

Bim The proportion of the concentrations of Bim to p53 is approximately $3 / 4$ [82]. Accord- ${ }_{322}$ ingly we take $B_{m 0}=3 / 4 \times P_{530}=2.0250 \times 10^{-5} \mathrm{~g} / \mathrm{cm}^{3}$.

Bcl-2 The concentration of Bcl-2 in healthy individuals is $2.5 \mathrm{ng} / \mathrm{ml}[52]$, that is $2.5 \times 10^{-9}{ }_{324}$ $\mathrm{g} / \mathrm{cm}^{3}$. Hence the concentration of Bcl-2 is $B_{c 0}=2.5 \times 10^{-9} \mathrm{~g} / \mathrm{cm}^{3}$.

Exosome In breast cancer, $10^{6}$ cancer cells release $5 \times 10^{8}$ exosomes in 24 hours [62]. Assum- 326 ing that the number of cancer cells in colorectal cancer is $4 \times 10^{8}$ per $\mathrm{cm}^{3}$, and taking the average 327 diameter of exosomes to be $70 \mathrm{~nm}$, we estimate the mass density of $E_{C}$ by $E_{C 0}=3.6 \times 10^{-10} \mathrm{~g} / \mathrm{cm}^{3}$. $\quad 328$

MiR-21, miR-92a, miR-23a and miR-1246 The range of molar concentration of miR- ${ }_{329}$ 21 in healthy individuals is $0.1-0.326 \mathrm{amol} / \mu \mathrm{L}$ [64, 83], and we take it to be $0.2 \mathrm{amol} / \mu \mathrm{L}$, that 330 is $\frac{0.2 \times 10^{-18}}{10^{-3}} \mathrm{~mol} / \mathrm{cm}^{3}=0.2 \times 10^{-3} \mathrm{nM}$. The molecular weight of $\mathrm{miR}-21$ is $7 \mathrm{kDa}$ 47]. Hence, by 331 Eq. (5.2), the concentration of miR-21 is $\left(0.2 \times 10^{-3}\right) \times 7 \times 10^{-9} \mathrm{~g} / \mathrm{cm}^{3}=1.4 \times 10^{-12} \mathrm{~g} / \mathrm{cm}^{3}$. The 332 concentrations of miR-92a, miR-23a and miR-1246 are approximately the same as concentration 333 of miR-21 [5]. Hence, $m_{i 0}=1.4 \times 10^{-12} \mathrm{~g} / \mathrm{cm}^{3}, i=1,2,3,4$.

Cancer cells and normal healthy cells We take $C_{M}=0.8 \mathrm{~g} / \mathrm{cm}^{3}, C_{0}=0.46 \mathrm{~g} / \mathrm{cm}^{3}\left[84{ }_{335}\right.$ and $N_{0}=0.14 \mathrm{~g} / \mathrm{cm}^{3}$.

\section{Parameter estimation}

In the sequel, in expressions of enhancement of the form $\frac{X}{K+X}$ or inhibition of the form $\frac{1}{1+X / K}, \quad 338$ the parameter $K$, the 'half-saturation' of $X$, will be taken to be the steady state of $X$. Thus 339 $K_{E E_{r}}=E_{r 0}, E_{R_{s} T}=T_{0}, K_{B_{n} A_{C}}=A_{C 0}, K_{M S}=S_{0}, K_{A P}=P_{0}, K_{P_{3} T}=T_{0}, K_{A p}=A_{p 0}, \quad 340$ $K_{C}=C_{0}, K_{B_{m} B_{c}}=B_{c 0}, K_{C M}=M_{0}, K_{C A}=A_{0}, K_{C A_{p}}=A_{p 0}$, and $K_{C B_{m}}=B_{m 0}$. However, we ${ }_{341}$ make an exception in the case of miRs: we assume that the inhibition by miRs is more significant 342 than inhibition by signaling proteins, and take $K_{T m_{1}}=K_{P m_{1}}=K_{B_{m} m_{1}}=m_{10} / 5=0.28 \times 10^{-12}{ }_{343}$ $\mathrm{g} / \mathrm{cm}^{3}, K_{A_{p} m_{2}}=m_{20} / 5=0.28 \times 10^{-12} \mathrm{~g} / \mathrm{cm}^{3}, K_{S m_{3}}=K_{G_{2} m_{3}}=m_{30} / 5=0.28 \times 10^{-12} \mathrm{~g} / \mathrm{cm}^{3}$ and 344 $K_{\mathrm{Pm}_{4}}=K_{B_{m} m_{4}}=m_{10} / 5=0.28 \times 10^{-12} \mathrm{~g} / \mathrm{cm}^{3}$.

Eq. 2.1): The half-life of EGFR ranges from 8 to 24 hours [49]. We take it to be 20 hours, 346 i.e. $t_{1 / 2}=5 / 6$ days, so that $d_{E}=\ln 2 / t_{1 / 2}=0.8318$ days $^{-1}$. From the steady state of Eq. 2.1) 347 with $K_{E E_{r}}=E_{r 0}$, we deduce that $\lambda_{E}=2 d_{E} E_{0}=1.1741 \times 10^{-3} \mathrm{day}^{-1} \cdot \mathrm{g} / \mathrm{cm}^{3}$. 
Eq.(2.2): The half-life of KRAS is 12 hours [50], that is, $t_{1 / 2}=1 / 2$ day, so that $d_{R s}=1.3863 \quad 349$ day $^{-1}$. From the steady state of Eq. 2.2 with $K_{R_{s} T}=T_{0}$, we find that $\lambda_{R_{s}}=2 d_{R_{s}} R_{s 0} / E_{0}=350$ $3.3001 \times 10^{-2}$ day $^{-1}$.

Eq. (2.3): The half-life of ERK is 24 hours [51], that is, $t_{1 / 2}=1$ day; hence $d_{E r}=0.6931352$ day $^{-1}$. From the steady state of Eq. (2.3), we then find that $\lambda_{E_{r}}=d_{E_{r}} E_{r 0} / R_{s 0}=3.248$ day $^{-1}$. 353

Eq.(2.4): The half-life of $\beta$-catenin is 1 hour [98], that is, $t_{1 / 2}=1 / 24$ day, so that $d_{B_{n}}={ }_{354}$ 16.6355 day $^{-1}$. From the steady state of 2.4 with $K_{B_{n} A_{C}}=A_{C 0}$, we find that $\lambda_{B_{n}}=2 d_{B_{n}} B_{n 0}={ }_{355}$ $1.4376 \times 10^{-3}$ day $^{-1}$.

Eq.(2.5): The half-life of c-Myc ranges from 15 to $50 \mathrm{~min}$ [53,54], and we take it to be 30min, 357 so that $t_{1 / 2}=0.0208$ day, and then $d_{M}=33.3244$ day $^{-1}$. From the steady state of Eq. (2.5), we 358 find that $\frac{1}{2}\left(\lambda_{M E_{r}} E_{r 0}+\lambda_{M B_{n}} B_{n 0}\right)=d_{M} M_{0}$. We assume that the activation of c-Myc through Ras- ${ }_{359}$ ERK pathway is stronger than activation through $\beta$-catenin, and take $\lambda_{M E_{r}} E_{r 0}=2 \lambda_{M B_{n}} B_{n 0}$. $\quad 360$ Hence $\lambda_{M E_{r}}=\frac{4}{3} d_{M} M_{0} / E_{r 0}=15.3211$ day $^{-1}$, and $\lambda_{M B_{n}}=\frac{2}{3} d_{M} M_{0} / B_{n 0}=6.9780$ day $^{-1}$. $\quad 361$

Eq.(2.6): The half-life of AKT ranges from 12 to 36 hours 55, 56. We take it to be 24362 hours, that is, $t_{1 / 2}=1$ day, so that $d_{A}=0.6931$ day $^{-1}$. From the steady state of Eq. (2.6) 363 we find that $\frac{1}{2}\left(\frac{1}{2} \lambda_{A E} E_{0}+\lambda_{A R_{s}} R_{s 0}\right)=d_{A} A_{0}$. We assume that the activation of PI3K pathway 364 by Ras is weaker than the activation by EGF-EGFR, and take $\lambda_{A E} E_{0}=4 \lambda_{A R_{s}} R_{s 0}$. Hence, 365 $\lambda_{A E}=\frac{8}{3} d_{A} A_{0} / E_{0}=2.4519 \times 10^{-3} \mathrm{day}^{-1}$ and $\lambda_{A R_{s}}=\frac{2}{3} d_{A} A_{0} / R_{s 0}=5.15 \times 10^{-2} \mathrm{day}^{-1}$.

Eq.(2.7): The half-life of the TKI drugs erlotinib, ASD9291 and sunitinib are 36, 50 and 40-60 hours 65]. We take the half-life of TKI to be 48 hours, that is, $t_{1 / 2}=2$ days. Hence $d_{T}=0.3466$ day $^{-1}$. From the steady state equation of Eq.2.7. with $K_{T m_{1}}=m_{10} / 5$, we find that $\lambda_{T}=6 d_{T} T_{0}=1.7687 \times 10^{-4}$ day $^{-1} \cdot \mathrm{g} / \mathrm{cm}^{3}$.

Eq. 2.8): The half-life of PTEN is 45 minutes [11,66], that is $t_{1 / 2}=0.03125$ day, so that 371 $d_{P}=22.1807$ day $^{-1}$. From the steady state of Eq. 22.8 with $K_{T m_{1}}=m_{10} / 5=0.56 \times 10^{-12} \mathrm{~g} / \mathrm{cm}^{3}, \quad 372$ we get $\lambda_{P}=36 d_{P} P_{0}=1.5012 \times 10^{-4}$ day $^{-1} \cdot \mathrm{g} / \mathrm{cm}^{-3}$.

Eq. (2.9): The half-life of Smad2 is $8.9 \mathrm{~h} 57]$ and the half-life of Smad4 ranges 6 from to 374 $8 \mathrm{~h}$ [67]. We take the half-life of the Smad complex to be 7 hours, that is $t_{1 / 2}=0.2917$ day, so that $d_{S}=2.3762$ day $^{-1}$. From the steady state of Eq. 2.9 with $K_{S m_{3}}=m_{30} / 5=0.28 \times 10^{-12}$ $\mathrm{g} / \mathrm{cm}^{3}$, it follows that $\lambda_{S}=6 d_{S} S_{0}=5.010 \times 10^{-5}$ day ${ }^{-1} \cdot \mathrm{g} / \mathrm{cm}^{-3}$.

Eq. 2.10): The half-life of p53 ranges from 5 to $20 \mathrm{~min}[58]$. We take it to be $15 \mathrm{~min}$, that is, $t_{1 / 2}=0.6250$ day, hence $d_{P_{53}}=1.1090$ day $^{-1}$. From the steady state of Eq. 2.10), we find that $\lambda_{P_{53}}=d_{P_{53}} P_{530}=2.9943 \times 10^{-6} \mathrm{day}^{-1} \cdot \mathrm{g} / \mathrm{cm}^{-3}$.

Eq. 2.11): The half-life of Apaf-1 is 1.81h [99], and the half-life of caspase-9 is 6.6h [59]. We assume that Apaf-1-caspase-9 apoptosome is as stable as caspase-9, and take the half-life of the apoptosome to be $6 \mathrm{~h}$, so that $t_{1 / 2}=0.25$ days. Then $d_{A p}=2.7726 \mathrm{day}^{-1}$. From the steady state of Eq. 2.11 with $K_{A_{p} m_{2}}=m_{20} / 5$, we conclude that $\lambda_{A_{p}}=6 d_{A_{p}} A_{p 0} / P_{530}=174.982$ day $^{-1}$.

Eq.(2.12): The half-life of Bim is $2.8 \mathrm{~h}$ 60.61, that is, $t_{1 / 2}=0.1167$ day, so that $d_{B_{m}}=5.9396$ 
day $^{-1}$. From the steady state of Eq. 2.12 with $K_{B_{m} B_{c}}=B_{c 0}$ and $K_{B_{m} m_{4}}=m_{40} / 5=0.56 \times 10^{-12}{ }_{386}$ $\mathrm{g} / \mathrm{cm}^{3}$ we get $\lambda_{B_{m}}=12 d_{B_{m}} B_{m 0}=1.4433 \times 10^{-4}$ day $^{-1} \cdot \mathrm{g} / \mathrm{cm}^{3}$. 387

Eq. 2.13): The rate of breakdown of exosomes upon contact with cancer cells is unknown. 388 We take this rate to be $d_{E c}=21.8$ day $^{-1}$. From the steady state of Eq. 2.13 with $K_{C}=C_{0}$, we ${ }_{389}$ find that $\lambda_{E c}=d_{E c} E_{C 0} /\left(2 C_{0}\right)=8.53 \times 10^{-9}$ day $^{-1}$. 390

Eqs.(2.14)-(2.17): The half-life of miRs is greater than 24 hours 63]; we take half-life of 391 miR-21, miR-23a, miR-1246 and miR-92a to be 30 hours, i.e. $t_{1 / 2}=1.25$ day, hence $d_{m_{i}}=0.5545392$ day $^{-1}, i=1,2,3$, 4. From the steady state of Eqs. 2.14-2.17) with $K_{C}=C_{0}$, we get $\lambda_{m_{i}}={ }_{393}$ $2 d_{m_{i}} m_{i 0} / E_{C 0}=1.82 \times 10^{-4}$ day $^{-1}, i=1,2,3,4$. When $E_{C}$ is degraded (at rate $d_{E}$ ) only a very 394 small concentration of $m_{i}$ is released, hence $\lambda_{m_{i}}$ is much smaller than $d_{E}$. 395

Eq. 2.18): We choose $\varepsilon=0.1$, as in 43. The most common mutations in CRC are APC, 396 p53, KRAS, PI3K and SMAD4 22 24. Mutations seem to occur more frequently in Ras-ERK 397 than in PI3K-AKT 22 24]. We accordingly assume that the proliferation rate of cancer cells 398 through the Ras-ERK pathway is higher than the proliferation rate through the PI3K-AKT 399 pathway, and take $\lambda_{C M}=2 \lambda_{C A}$. We also assume that

$$
\frac{1}{2} \lambda_{C M}+\frac{1}{2} \lambda_{C A}=\lambda_{C}
$$

and take $\lambda_{C}=0.46$ day $^{-1}$ [4]. Hence $\lambda_{C M}=(4 / 3) \lambda_{C}=0.6133$ day $^{-1}$ and $\lambda_{C A}=(2 / 3) \lambda_{C}={ }^{401}$ 0.3067 day $^{-1}$.

When cancer cells undergo invasion, the competition for space with normal healthy cells is ${ }^{403}$ low. From the steady state equation of Eq.2.18 with only cancer cells (i.e. with $N=0$ ) and ${ }^{404}$ $K_{C M}=M_{0}, K_{C A}=A_{0}, K_{C A p}=A p_{0}$ and $K_{C B_{m}}=B_{m 0}$, we get

$$
\frac{1}{2}\left(d_{C A_{p}}+d_{C B_{m}}\right)+d_{C}=\frac{1}{2} \lambda_{C}\left(1-\frac{C_{0}}{C_{M}}\right), \quad \text { or } \quad\left(d_{C A_{p}}+d_{C B_{m}}\right)+2 d_{C}=0.85 \lambda_{C} .
$$

We assume that apoptosis rate through intrinsic apoptosis pathways (Apaf-1/Caspace-9 and ${ }_{406}$ Bim) is higher than apoptosis through the extrinsic signaling pathway [100, and take $d_{C A_{p}}{ }^{407}$ and $d_{C B_{m}}$ to be larger than $d_{C}$, so that $d_{C A_{p}}=0.45 \times\left(0.85 \lambda_{C}\right), d_{C B_{m}}=0.45 \times\left(0.85 \lambda_{C}\right)$ and ${ }_{408}$ $2 d_{C}=0.1 \times\left(0.85 \lambda_{C}\right)$. Hence $d_{C A_{p}}=0.176$ day $^{-1}, d_{C B_{m}}=0.176$ and $d_{C}=0.0196$ day $^{-1} . \quad{ }^{409}$

Since we are modeling cancer growth (with competition by $N$ ), we increase the above param- ${ }_{410}$ eters $\lambda_{C M}$ and $\lambda_{C A}$ by a factor 1.5 in order to account for the fact that proliferating cells grow ${ }_{411}$ faster than migrating cells 4042 , but we do not change the degradation rates $d_{C A_{p}}, d_{C B_{m}}$ and ${ }_{412}$ $d_{C}$.

Eq. 2.19): Cancer cells can survive in hostile environment better than normal cells, so the ${ }_{414}^{44}$ apoptosis rate $d_{N}$ should be somewhat larger than $d_{C}$; we take $d_{N}=1.2 d_{C}=0.0235$ day $^{-1}$ and ${ }_{415}$ $\lambda_{N}=0.25 \lambda_{C}=0.115$ day $^{-1}$. 
Diffusion coefficients: We take $D_{C}=D_{N}=8.64 \times 10^{-7} \mathrm{~cm}^{2}$ day 48 . Diffusion of a ${ }^{417}$ sphere is inversely proportional to its diameter. We assume that the average diameter of exosome ${ }_{418}$ and cells are $70 \mathrm{~nm}$ and $10 \mu \mathrm{m}$ respectively. Then we get $D_{E_{C}}=\frac{8.6 \times 10^{-7}}{7 \times 10^{-3}}=1.23 \times 10^{-4} \mathrm{~cm}^{2} \quad{ }_{419}$ day $^{-1}$. By 101, we have the relation $D_{m_{1}}=\frac{M_{V}^{1 / 3}}{M_{m_{1}}^{1 / 3}} D_{V}$, where $D_{V}$ and $M_{V}$ are the diffusion ${ }_{420}$ coefficient and molecular weight of vascular endothelial growth factor (VEGF), respectively, and ${ }_{421}$ $D_{V}=8.64 \times 10^{-2}$ [48], and $M_{V}=24 k D a$ [102]. The molecular weight of miR-21 is $M_{m_{1}}=7 \quad{ }_{422}$ $\mathrm{kDa}$, hence $D_{m_{1}}=0.13028 \mathrm{~cm}^{2}$ day ${ }^{-1}$, and similarly $D_{m_{i}}=0.13028 \mathrm{~cm}^{2}$ day $^{-1}$, where $i=2,3,4 . \quad{ }^{423}$

\section{Appendix B. Computational method}

We employ moving mesh method [103 to numerically solve the free boundary problem for the tumor proliferation model, and do the simulations by Matlab. To illustrate this method, we take Eq. 2.19) as an example and rewrite it as the following form:

$$
\frac{\partial N(r, t)}{\partial t}=D_{N} \Delta N(r, t)-\operatorname{div}(\mathbf{u} N)+F,
$$

where $F$ represents the term on the right hand side of Eq. 2.19). Let $r_{i}^{k}$ and $N_{i}^{k}$ denote numerical approximations of i-th grid point and $N\left(r_{i}^{k}, t\right)$, respectively when $t=k \tau$, where $\tau$ is the size of time-step and $k$ is the time point. The discretization of Eq. (5.3) is derived by the fully implicit finite difference scheme:

$$
\frac{N_{i}^{k+1}-N_{i}^{k}}{\tau}=D_{N}\left(N_{r r}+\frac{N_{r}}{r_{i}^{k}}\right)-\left(\frac{u_{r}}{r_{i}^{k+1}}+u_{i}^{k+1}\right) N_{i}^{k+1}+F_{i}^{k+1}
$$

where $\left.N_{r}=\frac{h_{-1}^{2} N_{i+1}^{k+1}-h_{1}^{2} N_{i-1}^{k+1}-\left(h_{1}^{2}-h_{-1}^{2}\right) N_{i}^{k+1}}{h_{1}\left(h_{-1}^{-1}-h_{1} h_{-1}\right)}, N_{r r}=2 \frac{h_{-1} N_{i+1}^{k+1}-h_{1} N_{i-1}^{k+1}+\left(h_{1}-h_{-1}\right) N_{i}^{k+1}}{h_{1}\left(h_{1} h_{-1}-h_{-1}^{2}\right.}\right)$,

$u_{r}=\frac{h_{-1}^{2} u_{i+1}^{k+1}-h_{1}^{2} k_{i-1}^{k+1}-\left(h_{1}^{2}-h_{-1}^{2}\right) u_{i}^{k+1}}{h_{1}\left(h_{-1}^{2}-h_{1} h_{-1}\right)}, h_{-1}=r_{i-1}^{k+1}-r_{i}^{k+1}$ and $h_{1}=r_{i+1}^{k+1}-r_{i}^{k+1}$. The mesh moves by ${ }^{426}$ $r_{i}^{k+1}=r_{i}^{k}+u_{i}^{k+1} \tau$, where $u_{i}^{k+1}$ is solved by the velocity equation.

\section{References}

[1] Siegel RL, Miller KD, Jemal A. Cancer Statistics 2016. CA CANCER J CLIN. 2016;66:730 .

[2] Cancer Facts and Statistics. American Cancer Society. 2016;

[3] Burch JA, Soares-Weiser K, John DJBS, Duffy S, Smith S, Kleijnen J, et al. Diagnostic accuracy of faecal occult blood tests used in screening for colorectal cancer: a systematic review. J Med Screen. 2007;14(3):132-137. 
[4] Frydrychowicz M, Kolecka-Bednarczyk A, Madejczyk M, Yasar S, Dworacki G. Exosomesstructure, biogenesis and biological role in non-small-cell lung cancer. Scand J Immunol. 2015;81(1):2-10.

[5] Ogata-Kawata H, Izumiya M, Kurioka D, Honma Y, Yamada Y, Furuta K, et al. Circulating Exosomal microRNAs as Biomarkers of Colon Cancer. PLoS One. Apr 2014;9(4):e92921.

[6] Moshammer MI, Kalipciyan M, Bartsch R, Steger GG, Sedivy R, Mader RM. Exosomal microRNA transfer varies with specific microRNAs functional in colorectal cancer and cellular differentiation. Int J Clin Pharmacol Ther. Jan 2014;52(1):87-88.

[7] Roberts P, Der C. Targeting the Raf-MEK-ERK mitogen-activated protein kinase cascade for the treatment of cancer. Oncogene. 2007;26:3291-3310.

[8] Dhillon A, Hagan S, Rath O, Kolch W. MAP kinase signalling pathways in cancer. Oncogene. 2007;26:3279-3290.

[9] Krasinskas AM. EGFR Signaling in Colorectal Carcinoma. Pathology Research International. 2011;vol. 2011(Article ID 932932):6 pages.

[10] Shaw R, Cantley L. Ras, PI(3)K and mTOR signalling controls tumour cell growth. Nature. 2006;441:424-430.

[11] Faratian D, Goltsov A, Lebedeva G, Sorokin A, Moodie S, et al. Systems biology reveals new strategies for personalizing cancer medicine and confirms the role of PTEN in resistance to trastuzumab. Cancer Res. 2009;69(16):6713-6720.

[12] Fodde R, Smits R, Clevers H. APC, signal transduction and genetic instability in colorectal cancer. Nat Rev Cancer. Oct 2011;1(1):55-67.

[13] Colussi D, Brandi G, Bazzoli F, Ricciardiello1 L. Molecular Pathways Involved in Colorectal Cancer: Implications for Disease Behavior and Prevention. Int J Mol Sci. Aug 2013;14(8):16365-16385.

[14] Siegel PM, Massague J. Cytostatic and apoptotic actions of TGF-beta in homeostasis and cancer. Nat Rev Cancer. Nov 2003;3(11):807-821.

[15] Ikushima H, Miyazono K. TGFbeta signalling: a complex web in cancer progression. Nat Rev Cancer. Jun 2010;10(6):415-424.

[16] Pickup M, Novitskiy S, Moses HL. The roles of TGFbeta in the tumour microenvironment. Nat Rev Cancer. Nov 2013;13(11):788-799.

[17] Wang S, Zeng Y, Zhou JM, Nie SL, Peng Q, Gong J. MicroRNA-1246 promotes growth and metastasis of colorectal cancer cells involving CCNG2 reduction. Mol Med Rep. Jan 2016;13(1):273-280.

[18] Yang SY, Sales KM, Fuller B, Seifalian AM, Winslet MC. Apoptosis and colorectal cancer: implications for therapy. Trends Mol Med. May 2009;15(5):225-233. 
[19] Sinicrope FA, Rego RL, Okumura K, Foster NR, OConnell MJ, Sargent DJ, et al. Prognostic Impact of Bim, Puma, and Noxa Expression in Human Colon Carcinomas. Clin Cancer Res. Sept 2008;14(18):5810-5818.

[20] Hector S, Prehn JHM. Apoptosis signaling proteins as prognostic biomarkers in colorectal cancer: A review. Biochimica et Biophysica Acta. Apr 2009;1795(2):117-129.

[21] Huerta S, Goulet EJ, Livingston EH. Colon cancer and apoptosis. Am J Surg. Apr 2006;191(4):517-526.

[22] Fearon ER. Molecular Genetics of Colorectal Cancer. Annu Rev Pathol. Feb 2011;6:479507.

[23] Cai ZX, Tang XD, Gao1 HL, Tang C, Nandakumar V, Jones L, et al. APC, FBXW7, KRAS, PIK3CA, and TP53 Gene Mutations in Human Colorectal Cancer Tumors Frequently Detected by Next-Generation DNA Sequencing. J Mol Gene Med. Nov 2014;8(4):145.

[24] Yu J, Wu WKK, Li X, He1 J, Li XX, Ng SSM, et al. Novel recurrently mutated genes and a prognostic mutation signature in colorectal cancer. Gut. Apr 2015;64(4):636-645.

[25] Downward J. Targeting RAS signalling pathways in cancer therapy. Nat Rev Cancer. January 2003;3(1):11-22.

[26] Chiba M, Kimura M, Asari S. Exosomes secreted from human colorectal cancer cell lines contain mRNAs, microRNAs and natural antisense RNAs, that can transfer into the human hepatoma HepG2 and lung cancer A549 cell lines. Oncol Rep. Nov 2012;28(5):1551-1558.

[27] Ji H, Chen M, Greening DW, He W, Rai A, Zhang W, et al. Deep Sequencing of RNA from Three Different Extracellular Vesicle (EV) Subtypes Released from the Human LIM1863 Colon Cancer Cell Line Uncovers Distinct Mirna-Enrichment Signatures. PLoS One. Oct 2014;9(10):e110314.

[28] Matsumura T, Sugimachi K, Iinuma H, Takahashi Y, Kurashige J, Sawada G, et al. Exosomal microRNA in serum is a novel biomarker of recurrence in human colorectal cancer. Br J Cancer. Jul 2015;113(2):275-281.

[29] Yamada N, Tsujimura N, Kumazaki M, Shinohara H, Taniguchi K, Nakagawa Y, et al. Colorectal cancer cell-derived microvesicles containing microRNA-1246 promote angiogenesis by activating Smad 1/5/8 signaling elicited by PML down-regulation in endothelial cells. Biochim Biophys Acta. Nov 2014;1839(11):1256-1272.

[30] Ke TW, Wei PL, Yeh KT, Chen WTL, Cheng YW. MiR-92a promotes cell metastasis of colorectal cancer through PTEN-mediated PI3K/AKT pathway. Ann Surg Oncol. Aug 2015;22(8):2649-2655.

[31] MicroRNA-92a functions as an oncogene in colorectal cancer by targeting PTEN. Dig Dis Sci. Jan 2014;59(1):98-107. 
[32] Tsuchida A, Ohno S, Wu W, Borjigin N, Fujita K, Aoki T, et al. miR-92 is a key oncogenic component of the miR-17-92 cluster in colon cancer. Cancer Sci. Dec 2011;102(12):22642271.

[33] Yong FL, Wang CW, Roslani AC, Law CW. The Involvement of miR-23a/APAF1 Regulation Axis in Colorectal Cancer. Int J Mol Sci. Jul 2014;15(7):11713-11729.

[34] Wang J, Du Y, Liu X, Cho WC, Yang Y. MicroRNAs as Regulator of Signaling Networks in Metastatic Colon Cancer. BioMed Research International. 2015;vol. 2015(Article ID 823620):12 pages.

[35] Hrasovec S, Glavac D. MicroRNAs as Novel Biomarkers in Colorectal Cancer. Front Genet. Oct 2012;3(180):1-9.

[36] Yu G, li H, Wang X, Wu T, Zhu J, Huang S, et al. MicroRNA-19a targets tissue factor to inhibit colon cancer cells migration and invasion. Molecular and Cellular Biochemistry. Aug 2013;380(1):239-247.

[37] Cellura D, Pickard K, Quaratino S, Parker H, Strefford JC, Thomas GJ, et al. miR19CMediated Inhibition of Transglutaminase- 2 Leads to Enhanced Invasion and Metastasis in Colorectal Cancer. Mol Cancer Res. Jul 2015;13(7):1095-1105.

[38] Kim Y, Roh S, Lawler S, Friedman A. MiR451 and AMPK mutual antagonism in glioma cell migration and proliferation: a mathematical model. PLoS One. 2011;6(12):e28293.

[39] Salamon R, Backer J. PIP3: Tool of Choice for the Class I PI 3-kinases. Bioessays. 2013;35(7):602-611.

[40] Gao CF, Xie Q, Su YL, Koeman J, Khoo SK, et al. Proliferation and invasion: Plasticity in tumor cells. PNAS. 2005;102(30):10528-10533.

[41] Matus D, Lohmer L, Kelley L, Schindler A, Kohrman A, et al. Invasive cell fate requires G1 cell-cycle arrest and Histone Deacetylase-mediated changes in gene expression. Developmental Cell. 2015;35(2):162-174.

[42] Gil-Henn H, Patsialou A, Wang Y, Warren M, Condeelis J, et al. Arg/Abl2 promotes invasion and attenuates proliferation of breast cancer in vivo. Oncogene. 2013;32:26222630 .

[43] Jain HV, Clinton SK, Bhinder A, Friedman A. Mathematical modeling of prostate cancer progression in response to androgen ablation therapy. Proc Natl Acad Sci USA. 2011;108(49):19701-19706.

[44] Friedman A, Lolas G. Analysis of a mathematical model of tumor lymphangiogenesis. Math Models Methods Appl Sci. 2005;15(1):95-107.

[45] Chen D, Friedman A. A two-phase free boundary problem with discontinuous velocity: Application to tumor model. J Math Anal. 2013;399(1):378-393. 
[46] Hao W, Friedman A. The LDL-HDL Profile Determines the Risk of Atherosclerosis: A Mathematical Model. PLoS ONE. 2014;9(3):e90497.

[47] Bader AG, Brown D, Stoudemire J, Lammers P. Developing therapeutic microRNAs for cancer. Gene Therapy. 2011;18:1121-1126.

[48] Liao KL, Bai XF, Friedman A. Mathematical modeling of interleukin-27 induction of anti-tumor T cells response. PLoS ONE. 2014;9(3):e91844.

[49] Sorkin A, Duex JE. Quantitative analysis of endocytosis and turnover of epidermal growth factor (EGF) and EGF receptor. Curr Protoc Cell Biol. 2010;15(14).

[50] Shukla S, Allam US, Ahsan A, Chen G, Krishnamurthy PM, et al. KRAS protein stability is regulated through SMURF2: UBCH5 complex-mediated $\beta$-TrCP1 degradation. Neoplasia. 2014;16:115-128.

[51] Satoh M, Parent AD, Zhang JH. Inhibitory Effect With Antisense Mitogen-Activated Protein Kinase Oligodeoxynucleotide Against Cerebral Vasospasm in Rats. Stroke. 2002;33:775-781.

[52] Tarantino G, Scopacasa F, Colao A, Capone D, Tarantino M, Grimaldi E, et al. Serum Bcl2 concentrations in overweight-obese subjects with nonalcoholic fatty liver disease. World J Gastroenterol. Dec 2011;17(48):5280-5288.

[53] Luscher B, Eisenman RN. c-myc and c-myb protein degradation: effect of metabolic inhibitors and heat shock. Mol Cell Biol. Jun 1988;8(6):2504-2512.

[54] Arabi A, Rustum1 C, Hallberg E, Wright APH. Accumulation of c-Myc and proteasomes at the nucleoli of cells containing elevated c-Myc protein levels. Journal of Cell Science. Jan 2003;116:1707-1717.

[55] Lee JH, Shin SH, Kang S, Lee YS, Bae S. A novel activation-induced suicidal degradation mechanism for Akt by selenium. Int J Mol Med. 2008;21(1):91-97.

[56] Basso AD, Solit DB, Chiosis G, Giri B, Tsichlis P, et al. Akt Forms an Intracellular Complex with Heat Shock Protein 90 (Hsp90) and Cdc37 and Is Destabilized by Inhibitors of Hsp90 Function. J Biol Chem. 2002;277(42):39858-39866.

[57] Cui W, Zhou J, Dehne N, Brune B. Hypoxia induces calpain activity and degrades SMAD2 to attenuate TGF-btea signaling in macrophages. Cell \& Bioscience. Jul 2015;5:36.

[58] Giaccia AJ, Kastan MB. The complexity of p53 modulation: emerging patterns from divergent signals. Genes Dev. Oct 1998;12(19):2973-2983.

[59] von Roretz C, Lian XJ, Macri AM, Punjani N, Clair E, et al. Apoptotic-induced cleavage shifts $\mathrm{HuR}$ from being a promoter of survival to an activator of caspase-mediated apoptosis. Cell Death Differ. 2013;20:154-168. 
[60] Luciano F, Jacquel A, Colosetti P, Herrant M, Cagnol S, Pages G, et al. Phosphorylation of Bim-EL by Erk1/2 on serine 69 promotes its degradation via the proteasome pathway and regulates its proapoptotic function. Oncogene. 2003;22:6785-6793.

[61] Meller R, Cameron1 JA, Torrey DJ, Clayton1 CE, Ordonez AN, Henshall1 DC, et al. Rapid degradation of Bim by the ubiquitin-proteasome pathway mediates short-term ischemic tolerance in cultured neurons. J Biol Chem. Mar 2006;281(11):7429-7436.

[62] Riches A, Campbell E, Borger E, Powis S. Regulation of exosome release from mammary epithelial and breast cancer cells - a new regulatory pathway. Eur J Cancer. 2014;50(5):10251034 .

[63] McDonald D. Understanding miRNA turnover: a study of miRNA lalf-life. Broad Insitute. 2010 ;.

[64] Komatsu S, Ichikawa D, Takeshita H, Tsujiura M, Morimura R, et al. Circulating microRNAs in plasma of patients with oesophageal squamous cell carcinoma. Br J Cancer. 2011;105(1):104-111.

[65] Peters S, Zimmermann S, Adjei AA. Oral epidermal growth factor receptor tyrosine kinase inhibitors for the treatment of non-small cell lung cancer: Comparative pharmacokinetics and drugCdrug interactions. Cancer Treatment Reviews. 2014;40:917-926.

[66] Vazquez F, Ramaswamy S, Nakamura N, Sellers WR. Phosphorylation of the PTEN tail regulates protein stability and function. Mol Cell Biol. 2000;20(14):5010-5018.

[67] Saha D, P K Datta RDB. Oncogenic ras represses transforming growth factor-beta /Smad signaling by degrading tumor suppressor Smad4. J Biol Chem. Aug 2001;276(31):2953129537.

[68] Fujioka A, Terai K, Itoh RE, Aoki K, Nakamura T, et al. Dynamics of the Ras/ERK MAPK cascade as monitored by fluorescent probes. J Biol Chem. 2006;281(13):8917-8926.

[69] Jr RR. ERK1/2 MAP kinases: Structure, function, and regulation. Pharmacological Research. 2012;66:105-143.

[70] Akinleye A, Furqan M, Mukhi N, Ravella P, Liu D. MEK and the inhibitors: from bench to bedside. J Hematol Oncol. 2013;6:27.

[71] Kang H, Crawford M, Fabbri M, Nuovo G, Garofalo M, Nana-Sinkam SP, et al. A mathematical model for MicroRNA in lung cancer. PLOS ONE. 2013;8(1):e53663.

[72] Spotts GD, Patel SV, Xiao Q, Hann SR. Identification of downstream-initiated c-Myc proteins which are dominant-negative inhibitors of transactivation by full-length c-Myc proteins. Mol Cell Biol. Mar 1997;17(3):1459-1468.

[73] Barua D, Hlavacek WS. Modeling the effect of APC truncation on destruction complex function in colorectal cancer cells. PLoS Comp Biol. Sept 2013;9(9):e1003217. 
[74] Elliott KL, Catimel B, Church NL, Coates JL, Burgess AW, Layton MJ, et al. Immunopurification of adenomatous polyposis coli (APC) proteins. BMC Research Notes. Oct 2013;6:429.

[75] Tan CW, Gardiner BS, Hirokawa Y, Smith DW, Burgess AW. Analysis of Wnt signaling $\beta$-catenin spatial dynamics in HEK293T cells. BMC Syst Biol. Apr 2014;8(44):1-18.

[76] Legewie S, Herzel H, Westerhoff HV, Bluthgen N. Recurrent design patterns in the feedback regulation of the mammalian signalling network. Mol Syst Biol. 2008;17:190.

[77] Leander R, Dai S, Schlesinger LS, Friedman A. A mathematical model of CR3/TLR2 crosstalk in the context of francisella tularensis infection. PLOS Compt Biol. 2012;8(11):e1002757.

[78] Schmierer B, Tournier AL, Bates PA, , Hill CS. Mathematical modeling identifies Smad nucleocytoplasmic shuttling as a dynamic signal-interpreting system. Proc Natl Acad Sci USA. May 2008;105(18):6608-6613.

[79] Jayaraman L, Massague J. Distinct oligomeric states of SMAD proteins in the transforming growth factor-b pathway. J Biol Chem. Dec 2000;275(52):40710-40717.

[80] Adrover E, Maestro ML, Sanz-Casla MT, del Barco V, Cerdan J, Fernndez C, et al. Expression of high p53 levels in colorectal cancer: a favourable prognostic factor. Br J Cancer. Sept 1999;81(1):122-126.

[81] Reubold TF, Wohlgemuth S, Eschenburg S. A new model for the transition of APAF-1 from inactive monomer to caspase-activating apoptosome. J Biol Chem. 2009;284(47):3271732724 .

[82] Zhou CH, Zhang XP, Liu F, Wang W. Modeling the interplay between the HIF-1 and p53 pathways in hypoxia. Scientific Reports. Sept 2015;5(13834).

[83] Komatsu S, Ichikawa D, Tsujiura M, Konishi H, Takeshita H, et al. Prognostic impact of circulating miR-21 in the plasma of patients with gastric carcinoma. Anticancer Res. 2013;33(1):271-276.

[84] Szomolay B, Eubank T, Roberts RD, B MC, A F. Modeling the inhibition of breast cancer growth by GM-CSF. J Theor Biol. 2012;303:141-151.

[85] Oue N, Anami K, Schetter AJ, Moehler M, Okayama H, Khan MA, et al. High miR-21 expression from FFPE tissues is associated with poor survival and response to adjuvant chemotherapy in colon cancer. Int J Cancer. Apr 2014;134(8):1926-1934.

[86] Deng J, Lei1 W, Fu JC, Zhang L, Li JH, Xiong JP. Targeting miR-21 enhances the sensitivity of human colon cancer HT-29 cells to chemoradiotherapy in vitro. Biochem Biophys Res Commun. Jan 2014;443(3):789-795.

[87] Longley DB, Harkin DP, Johnston PG. 5-fluorouracil: mechanisms of action and clinical strategies. Nat Rev Cancer. May 2003;3(5):330-338. 
[88] Alcindor T, Beauger N. Oxaliplatin: a review in the era of molecularly targeted therapy. Curr Oncol. Feb 2011;18(1):18-25.

[89] Park W, Amin ARMR, Chen ZG, Shin DM. New perspectives of curcumin in cancer prevention. Cancer Prev Res (Phila). May 2013;6(5):387-400.

[90] Kanwar SS, Yu Y, Nautiyal J, Patel BB, Padhye S, Sarkar FH, et al. DifluorinatedCurcumin (CDF): A Novel Curcumin Analog is a Potent Inhibitor of Colon Cancer StemLike Cells. Pharm Res. Apr 2011;28(4):827-838.

[91] Ramasamy TS, Ayob AZ, Myint3 HHL, Thiagarajah S, Amini F. Targeting colorectal cancer stem cells using curcumin and curcumin analogues: insights into the mechanism of the therapeutic efficacy. Cancer Cell Int. Oct 2015;15:96.

[92] An T, Qin S, Xu Y, Tang Y, Huang Y, et al. Exosomes serve as tumour markers for personalized diagnostics owing to their important role in cancer metastasis. J Extracell Vesicles. 2015;4:27522.

[93] Properzi F, Logozzi M, Fais S. Exosomes: the future of biomarkers in medicine. Biomark Med. 2013;7(5):769-778.

[94] Marino S, Hogue I, Ray C, Kirschner D. A methodology for performing global uncertainty and sensitivity analysis in systems biology. J Theor Biol. 2008;254(1):178-196.

[95] CTNNB1 (human). PhosphoSitePlus;.

[96] Cantrell DA. Phosphoinositide 3-kinase signalling pathways. J Cell Sci. 2001;114(8):14391445 .

[97] Meyer R, D’Alessandro LA, Kar S, Kramer B, She B, et al. Heterogeneous kinetics of AKT signaling in individual cells are accounted for by variable protein concentration. Front Physiol. 2012;3:1-14.

[98] Salic A, Lee E, Mayer L, Kirschner MW. Control of $\beta$-catenin stability: reconstitution of the cytoplasmic steps of the wnt pathway in Xenopus egg extracts. Mol Cell. Mar 2000;5(3):523-532.

[99] Vreeland AC, Yu S, Levi L, de Barros D, Noya N. Transcript Stabilization by the RNABinding Protein HuR Is Regulated by Cellular Retinoic Acid-Binding Protein 2. Molecular and Cellular Biology. 2014;34(12):2135-2146.

[100] Mcllwain DR, Berger T, Mak TW. Caspase functions in cell death and disease. Cold Spring Harb Perspect Biol. 2013;5(4):a008656.

[101] Young ME. Estimation of diffusion coefficients of proteins. Biotechnology and Bioengineering. 1980;XXII:947-955.

[102] Shui YB, Wang X, Hu JS, Wang SP, Garcia CM, et al. Vascular endothelial growth factor expression and signaling in the lens. Invest Ophthalmol Vis Sci. 2003;44(9):3911-3919. 
[103] D'Acunto B. Computational Methods for PDE in mechanics. Series on Advances in Mathematics for Applied Sciences-Vol.67. Word Scientific; 2004. 